Mississippi State University

Scholars Junction

8-6-2005

\title{
Impact of a School-Home Partnership Model at a Small Rural Elementary School in Georgia
}

Janice Davis Waters

Follow this and additional works at: https://scholarsjunction.msstate.edu/td

\section{Recommended Citation}

Waters, Janice Davis, "Impact of a School-Home Partnership Model at a Small Rural Elementary School in Georgia" (2005). Theses and Dissertations. 5297.

https://scholarsjunction.msstate.edu/td/5297

This Dissertation - Open Access is brought to you for free and open access by the Theses and Dissertations at Scholars Junction. It has been accepted for inclusion in Theses and Dissertations by an authorized administrator of Scholars Junction. For more information, please contact scholcomm@msstate.libanswers.com. 


\title{
IMPACT OF A SCHOOL-HOME PARTNERSHIP MODEL AT A SMALL RURAL ELEMENTARY SCHOOL IN GEORGIA
}

By

\author{
Janice Davis Waters
}


IMPACT OF A SCHOOL-HOME PARTNERSHIP MODEL AT A SMALL RURAL ELEMENTARY SCHOOL IN GEORGIA

\author{
By
}

Janice Davis Waters

A Dissertation
Submitted to the Faculty of
Mississippi State University
In Partial Fulfillment of the Requirements
For the Degree of Doctor of Philosophy
In Elementary, Middle, \& Secondary School Administration
In the Department of Instructional Systems, Leadership \& Workforce Development

Mississippi State, Mississippi

August 2005 
Name: Janice Davis Waters

Date of Degree: August 6, 2005

Institution: Mississippi State University

Major Field: Educational Leadership

Major Professor: Dr. W. C. Johnson

Title of Study: $\quad$ IMPACT OF A SCHOOL-HOME PARTNERSHIP MODEL AT A SMALL RURAL ELEMENTARY SCHOOL IN GEORGIA

Pages in Study: 136

Candidate for Degree of Doctor of Philosophy

This study investigated the impact of the School-Home Partnership Model at Metter Intermediate School, a small rural school in southeast Georgia. The subjects of this study were parents, students, and teachers of the school. In particular, this study investigated the impact of the School-Home Partnership Model on "at-risk" students. For the purpose of this study the term "at-risk" student is defined to mean a student identified as being below' grade level in reading and/or math based on the guidelines of Georgia's Early Intervention Program (EIP). The term "at-risk" student as used in this study also means a student identified as a special education student according to the Individuals with Disabilities Education Act (IDEA). Quantitative methods and interviews were used to collect and analyze data. These methods consisted of document analysis, surveys, and interviews.

The investigation results show that parents, students, and teachers had very positive attitudes toward the school. Extensive communication strategies were utilized 
between the home and school. Children's attendance in school improved, while the number of discipline referrals to the school office increased for "at-risk" students. Quantitative data based on Criterion-Referenced Competency Tests (CRCT) showed limited changes. Report card grades showed improvements in grades for "at-risk" students in reading, math, and spelling. Parents of both non "at-risk" and "at-risk" students overwhelming believed they could better assist their children learn if teachers provided more ideas of ways they could help their children at home. 


\section{DEDICATION}

I dedicate this dissertation to my husband, Matthew Waters, my husband, friend, and supporter for over thirty years. He continues to enable me to accomplish my dreams.

I also dedicate this dissertation in memory of my mother, Johnnie Nance Davis.

Her graciousness, goodness, and love touched my heart and everyone who was fortunate enough to know her. 


\section{ACKNOWLEDGMENTS}

I express sincere thanks to my dissertation chair and advisor, Dr. W. C. Johnson, for his knowledge, diligence, and patience. My gratitude also is extended to the other members of my committee, Dr. Vincent McGrath, Dr. James Adams, and Dr. James E. Davis.

I am very appreciative of the moral support from my family. My son, Steve, and my son and daughter-in-law, Dave and Mary Ellen Waters, my father, Cecil Davis, and my sister, Dana Davis, surrounded me with love and patience. Special thanks are extended to Dr. Felix Johnston, superintendent of Candler County Schools in Metter, Georgia. Students, parents, and teachers of Metter Intermediate School will always hold a special place in my heart. Their support, patience, and love enabled me to accomplish this project. Charles K. Clark, my friend and special supporter of Metter Intermediate School, generously helped in many ways. Charlotte Jones Coursey and Dr. Nancy Norton, my friends and former bosses, enabled this project. I am thankful to Dr. Kent Wolfe, Marketing Specialist, Center for Agribusiness and Economic Development, the University of Georgia, for providing technical assistance. Special thanks are also extended to friends, Kelli Taylor and Jackie White, who provided thorough and capable assistance. 


\section{TABLE OF CONTENTS}

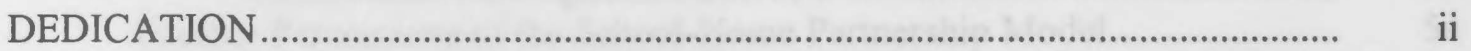

ACKNOWLEDGMENTS …………................................................................. iii

LIST OF TABLES ................................................................................. vii

CHAPTER

I. INTRODUCTION …………..............................................................

Statement of the Problem.................................................................................

Justification for the Study ..............................................................................

Research Design................................................................................................

Other Pertinent Information ..........................................................................

II. REVIEW OF LITERATURE ................................................................ 10

Conceptual Frameworks ............................................................................. 11

Parent Involvement Strategies ........................................................................ 15

School Reform Initiatives ................................................................................ 23

Summary of Related Literature...................................................................... $\quad 26$

III. METHODS AND PROCEDURES............................................................. 29

Research Design......................................................................................... 29

Document Examination ............................................................................ 31

Teacher Perceptions of the School-Home Partnership Model......................... 33

Student Perceptions of the School-Home Partnership Model.......................... 34

Parent Perceptions of the School-Home Partnership Model............................ $\quad 35$

Key Informants ............................................................................................... 37 
IV. FINDINGS AND DISCUSSION ........................................................... 39

Document Analysis....................................................................................... 41

Report Card Grades........................................................................... 41

Student Attendance Records ................................................................. 45

Criterion-Referenced Competency Tests (CRCT) .............................. 47

Behavioral Referrals to the School Office ......................................... $\quad 50$

Parent/Staff Participation Records ...................................................... 53

Teacher Perceptions of the School-Home Partnership Model.......................... $\quad 54$

Student Perceptions of the School-Home Partnership Model.......................... $\quad 60$

Parent Perceptions of the School-Home Partnership Model............................ 67

Key Informant Interviews .......................................................................... 77

V. SUMMARY, IMPLICATIONS, AND RECOMMENDATIONS ................ 90

Summary of the Findings.............................................................................. 91

Implications............................................................................................... 96

Recommendations.................................................................................... 97

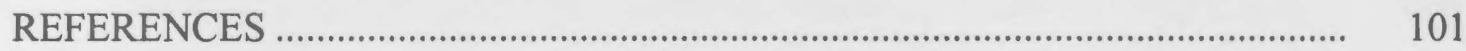

\section{APPENDIX}

A. Approval Documents ................................................................................. 105

B. Teacher Survey ......................................................................................... 108

C. Informed Consent Document for Teacher Survey .......................................... 112

D. Student Survey (“At-Risk” Students) ………………………....................... 114

E. Student Survey (Non “At-Risk” Students) ……............................................ 117

F. Informed Consent Document for Student and Parent Surveys ...................... 120

G. Assent Document for Student Surveys ........................................................ 123

H. Parent Survey (for “At-Risk” Students).......................................................... 125 
I. Parent Survey (for Non “At-Risk” Students).................................................. 129

J. Informed Consent Document for Teacher Interviews .................................... 133

K. Interview Questions for Teachers ............................................................. 135 


\section{LIST OF TABLES}

TABLE

Page

1. Means \& Standard Deviations for Report Card Grades by Years for Risk Groups

2. Means \& Standard Deviations for Report Card Grades by Years for Total Class

3. Means \& Standard Deviations for Report Card Grades by Semesters for

Risk Groups

4. Means \& Standard Deviations for Report Card Grades by Semesters for

Total Class

5. Means \& Standard Deviations for Days Absent by Years for Risk Groups .

6. Means \& Standard Deviations for Days Absent by Years for Total Class....

7. Means \& Standard Deviations for Behavior Referrals by Years for Risk Groups

8. Means \& Standard Deviations for Behavior Referrals by Years for Total Class

9. Means \& Standard Deviations for Behavior Referrals by Semesters for Risk Groups

10. Means \& Standard Deviations for Behavior Referrals by Semesters for Total Class

11. Parent Participation by Years for Selected Events

12. Perceptions of the School - Teachers

13. Perceptions of the School - Non "At-Risk" Students.

14. Perceptions of the School - "At-Risk" Students 
15. Perceptions of the School - Parents of Non "At-Risk" Students................. 71

16. Perceptions of the School - Parents of "At-Risk" Students ....................... 75 


\section{CHAPTER I \\ INTRODUCTION}

Parent involvement has many positive educational outcomes because the family regardless of its composition, economic standing, and educational background is the child's first and most important teacher. Davies (1991) identifies three themes of parent involvement: (1) successful schooling for students through impact on achievement, attendance, and behavior in school; (2) optimal development of the students in emotional, social and cognitive domains; and (3) shared responsibility for education between the home and the school.

The themes identified by Davies (1991) are evident in many reform initiatives including constructivist learning, charter schools, school choice, site-based management, parent involvement in individual education plans (IEP's) for students staffed into special education, school councils that include parents and other community members, and service integration initiatives such as Georgia's Family Connection. The term "Family Connection" refers to a nonprofit, public/private partnership created by the State of Georgia to improve the lives of Georgia's children, families and communities (Family Connection Partnership, n.d.). Connecting with families is instrumental in the establishment of a supportive school setting that can provide relevant, meaningful learning opportunities. 
Epstein, Coates, Salinas, Sanders, and Simon (1997) identified six types of parent involvement necessary for positive home-school relations: (1) basic parent responsibilities which include child safety and health, discipline, supervision, and learning at home; (2) responsibility of schools to communicate with parents; (3) parent involvement at school such as serving as volunteers and attending PTO-type activities; (4) parent involvement in specialized learning activities at home; (5) parent involvement in school governance and decisions; (6) participation in collaborative efforts between the school and the community in order to strengthen effectiveness of the school and the family. According to these writers, the challenge is to successfully establish homeschool activities that are inclusive of all families.

Blendinger and Jones (2003) reduced the Epstein, et al. (1997) model to three key components: communicating with parents, enabling parents to help their children with learning activities at home, and encouraging parents to participate at school. These three components in addition to the commitment of time, resources, and a strong belief in the importance of involving families are important because they affect student achievement, attitudes, and behavior.

Parent involvement theorists like Davies (2001), Epstein, et al. (1997) and Blendinger and Jones (2003) inspired this researcher to develop a school-home partnership model for a rural school in Georgia. The model was developed and implemented in 2001. 


\section{Statement of the Problem}

Approximately three years ago, Metter Intermediate School administrators created a School-Home Partnership Model for the purpose of increasing the involvement of families in their children's education in order to improve academic achievement and behavior. The problem, however, was that school officials did not know if the partnership model that was created increased parent involvement, improved students' academic success, or promoted appropriate student behavior.

Metter Intermediate School, a small rural school in southeast Georgia with an enrollment of two hundred eighty students in grades four and five, served an economically depressed population. The racial composition of the school was fifty percent white (non Hispanic), thirty-eight percent Black, ten percent Hispanic, and two percent classified as "other". Approximately thirty-seven percent of the students were in the Early Intervention Program. This meant that this population was below grade level performance in reading and/or math. Ten percent of the students were identified as special education students and seven percent were identified as gifted. During the 20012002 school year, seventy-six percent of the students were eligible for free and reduced meals.

This study investigated the impact of the School-Home Partnership Model created for Metter Intermediate School and used from fall 2001 to spring 2004 in relation to nine specific items: 
1. Student scores on the Georgia Criterion-Referenced Tests (Georgia Department of Education, 1999).

2. Student grades on report cards in four key academic areas: English, reading, spelling, and mathematics.

3. Student daily attendance at school.

4. Student behavior in relation to discipline referrals to the school office.

5. Parent and staff participation in parent-teacher meetings.

6. Parent participation in school activities and events.

7. Student perceptions of the school.

8. Teacher perceptions of the school.

9. Parent perceptions of the school.

The investigation also examined the impact of the School-Home Partnership Model on "at-risk" students in particular. For the purpose of this study the term "at-risk" student was defined to mean a student identified as below grade level in reading and/or math based on the guidelines of Georgia's Early Intervention Program (EIP). The term "at-risk" student was used in this study also meant a student identified as a special education student according to the Individuals with Disabilities Education Act (IDEA). An "at-risk" student was generally a student who was in danger of not completing his or her education with an adequate level of skills. Common risk factors were grade retention, low achievement, behavior problems, low socioeconomic status, and poor attendance (Slavin, 1989). 


\section{Justification for the Study}

Although researchers and practitioners agree that family involvement holds substantial potential for improving the education of students (Edwards, 1999; Blendinger \& Jones, 2003; Epstein, 1995; Swap, 1993), establishing home-school connections is difficult. This study was important because it provided insight into practical ways to establish home-school connections. Although over thirty years of research (Henderson and Berla, 1994) indicates the importance of family involvement in children's education, implementation of effective programs is dismal (Watkins, 1997). The development of practical, effective models for family involvement holds much promise for improving teaching and learning, but have yet to be developed.

Challenges and barriers exist that must be overcome if parents and families are to become full partners in the education of their children. An increasingly diverse population results in greater differences in language, values, and beliefs between families and schools (Riehl, 2000). This complicates communication and understanding at a time when schools are facing increasing pressure to educate all children to their fullest potential. Economic reality that leads to more mothers and other significant caregivers joining the work force results in less time for meeting with school personnel (Heymann \& Earle, 2000). Parents in lower-paying jobs often lack job benefits that allow release of time from work in order to attend activities at schools. An additional challenge is to prevent continuing cycles of school failure and limited family involvement with 
schools. Barriers created by parents' negative experiences with school when they were students can result in decreased contact between the home and school. Appropriate intervening processes are needed to prevent intergenerational parallelism (Kaplan, Liu, Kaplan, 2000).

\section{$\underline{\text { Research Design }}$}

This investigation was a study focusing on the impact of a School-Home Partnership Model at Metter Intermediate School. In an effort to increase the involvement of families in their children's education, Metter Intermediate School administrators developed the School-Home Partnership Model. The model was based primarily on Reaching Out to Families (Blendinger \& Jones, 2003) and Epstein's (1995) descriptions of overlapping spheres of influence. The assumptions of the model were: (1) establishment of mutual respect and trust among the home, school, and community enables the collaboration which leads to school and student improvement; (2) combined resources of the home, school, and community complement each other and increase the opportunities for school and student success; and (3) school staff have primary responsibility for setting the tone for positive, on-going connections with the home and community.

According to the model, effective communication can be established by a variety of steps. The first step involves making parents and community members feel welcome in the school. A warm, inviting, family-like atmosphere that includes many opportunities 
for parents, community, students, and teachers to become acquainted with each other is critical. A spirit of respect and cooperation should be evident when responding to problems, concerns, and requests. Communication with parents about student assignments, student progress, and ways to help with academics should be shared through such methods as parent-teacher conferences, monthly newsletters, electronic mail, folders of work for parent review, individual notes, phone calls, written comments in student agendas or homework notebook, parent meetings, and school visitation.

Collaboration with the community enhances and expands the school program. Mutual cooperation increases pertinent information to families about community events and services, utilizes school and community members to provide knowledge and information to each other, strengthens school and business partnerships, and provides opportunities for students to serve their community. Partnership efforts are strengthened as good news about collaborative projects and events are shared with the community.

An integral part of the School-Home Partnership Model was parent education through varied planned contacts. The planned activities should be based upon the particular needs and interests of the parents. The school staff can greatly enhance parent leadership efforts through support of the Parent Teacher Organization (PTO), their meetings, and planned student performances. Besides providing incentive for parents to attend PTO meetings, students are benefited by having opportunities to perform for an audience.

The establishment of mutual respect and trust enables the participation of parents and community members in school decision-making and advocacy. An essential part of 
this effort is to keep parents and the community informed about meetings of the board of education, school council, and the Parent Teacher Organization (PTO). Such outreach efforts as mailing school newsletters to board of education members and school council members help to set a tone of sharing and cooperation.

The School-Home Partnership Model was designed to encourage and solicit family and community members to donate their time, talents, and resources to support the school program. Ways to be involved included, for example, assistance with office duties, mentoring, and assisting with units of study through providing instructional support, participation in school events such as Book Fairs and field trips.

The focus of the School-Home Partnership Model was to provide multiple opportunities for students, parents, and teachers to work together for the improvement of student and school success. These varied opportunities for all constituents to participate, serve, grow, and learn is instrumental to school reform.

For this study of the School-Home Partnership Model quantitative methods and interviews were used. Subjects included the students, parents of the students, and teachers in Metter Intermediate School, a small rural elementary school in Georgia. Document analysis was accomplished by reviewing student report card grades, standardized test scores, behavioral referrals to the school office, student attendance in school, and parent participation records. Parents of students, students, and teachers completed school perception surveys that contained both closed-ended statements and open-ended questions. Structured interviews were conducted with teachers in the school. 
This study also investigated the impact of the School-Home Partnership Model on "at-risk" students in particular. For the purpose of this study the term "at-risk" student was defined to mean a student identified as being below grade level in reading and/or math based on the guidelines of Georgia's Early Intervention Program (EIP). The term "at-risk" student as used in this study also meant a student identified as a special education student according to the Individuals with Disabilities Education Act (IDEA).

\section{Other Pertinent Information}

Chapter II of this document addresses a selected review of literature related to parent involvement. Chapter III presents the research design with particular emphasis on data collection and analysis procedures. The study's findings are reported and discussed in Chapter IV. Chapter V presents a summary of the findings, conclusions, limitations, and recommendations.

Readers of this study should note that terms are defined in the text as they occur when special clarification is required. 


\section{CHAPTER II}

\section{REVIEW OF LITERATURE}

This study focused on the impact of a School-Home Partnership Model at a small, rural elementary school in Georgia. Essential involvement concepts developed by Blendinger and Jones (2003) and Epstein's (1995) hypothesis of overlapping spheres of influence were the basis for the model used in this study.

The purpose of the model was to increase the involvement of families in their children's education. The assumptions of the model are: (a) establishment of mutual respect and trust among the home, school, and community enables the collaboration which leads to school and student improvement; (b) combined resources of the home, school, and community complement each other and increase the opportunities for school and student success; and (c) school staff have primary responsibility for setting the tone for positive, on-going connections with the home and community.

Chapter II presents a review of relevant literature in four sections: (a) conceptual frameworks, (b) parent involvement strategies, (c) school reform initiatives, and (d) summary of related literature. Information about school reform initiatives is included because of the researcher's emphasis on practical applications of home, school, and community partnerships. 


\section{Conceptual Frameworks}

Gordon, Epstein, Blendinger, and Jones are four theorists in the area of parent involvement whose works will be addressed in this section. According to Davies (2001), involving parents in their children's education is critical if school reform is to result in students' increased academic success and social development.

Gordon's theories (Gordon \& Breivogel, 1976) about involving parents in their children's education have been a major influence in promoting positive home-school relations. In his earliest works, Gordon focused on improving the home learning environments by using paraprofessionals as home visitors. Later, he expanded his earlier focus by developing broad-based, comprehensive programs. Gordon theorized numerous roles for parents such as parents as teachers of their own child, as paraprofessionals, as decision-makers, as adult learners, as an audience at school events, and as volunteers in classrooms or the school library. Gordon emphasized parent involvement programs that are responsive to parents and encourage participatory democratic ideals. He believed programs should be designed to change parents' behavior and the behavior of the organizations with which the parent interacts (Olmsted, Rubin, True, \& Revicki, 1980).

In addition to emphasizing a comprehensive approach to parental involvement, Gordon addressed the limitations of what he called the deficit model of parent involvement. According to the deficit model, some environments need repair because they lack adequate stimulation for children. Gordon viewed the deficit model as over simplifying the home environment. Instead of viewing the home in deficit terms, he 
encouraged recognition that the home environment influences and is, in turn, influenced by community agencies such as schools, neighborhood centers, and businesses.

In the early 1990's, Epstein (1992) conceptualized four distinct ways of approaching the relationship between the school and the home: separate, sequenced, embedded, or overlapped. She believed that each of the four ways presented special challenges for school leaders. The separate influence is characterized by clear boundaries and contributions between families and schools. From this perspective, little contact exists between the home and the school.

The sequenced perspective is a variation of this theme. It includes critical stages when teachers and parents, at various points in time, contribute to the development and education of children. The sequenced perspective includes early childhood as the parents' domain, and school-aged children as the school's domain. As children progress to young adulthood they become more responsible for their own education. Epstein further contends these two perspectives have diminished as more children at younger ages are placed in daycare situations and parents become unwilling to have limited influence on their children's learning.

The embedded perspective focuses on the child's unique characteristics as the center of a micro-system. In this role, the child interacts with the home, church, and other various organizations. In turn, the child is influenced by and influences his environments as he encounters the interconnectedness of numerous variables in the environment. This interconnectedness is important and critical to the child's development. 
The overlapping perspective is characterized by family and school relationships that influence the development of children. Specific practices, such as communication strategies between the home and school through newsletters and parent-teacher conferences, affect the overlapping spheres of influence of home and school. The amount of overlap is affected by such factors as the characteristics of families, the history and culture of the school, and the grade levels of children.

In the later 1990's, Epstein (1995) focused more on the overlapping aspects of her earlier model. She conceptualized a model of family involvement based on overlapping spheres of influence. The model recognizes the family, the school, and the community as the three major contexts for children's growth and development. The spheres are pulled apart or pushed together based on the skills, practices, policies, and influences of the family, school, and community. The child's learning and development are viewed as the center of all efforts of these overlapping spheres. The needs of the child are central to the partnership since they influence the efforts of the partnership.

Epstein contended that the main reason for family, school, and community partnerships is to create conditions that enable students' success in school and in adulthood. Successful partnerships improve school programs and school climate, provide family services and support, increase parenting skills and leadership, connect families with others in the school and in the community, and help teachers with their work. Good interpersonal relations between teachers and parents are essential and form the basis for establishing trust and respect. Children are the beneficiaries of such partnership efforts. 
Moreover, partnerships motivate and encourage children to do their best academically and socially.

Blendinger and Jones, two Colorado educators, teamed in the 1980's for the purpose of developing a clear, concise conceptual framework for understanding the benefits of parent involvement in children's education. After many years of actionoriented research, Blendinger and Jones (2003) developed an easy to understand, practical means for effective school-home collaboration based on communicating with parents, enabling parents to help children learn at home, and promoting parent participation at school. They contend that these three areas are mutually interdependent and require commitment, time, and resources.

According to Blendinger and Jones (2003), every communication with the home is an opportunity to build positive, productive relationships. Both formal and informal communication such as written notes to individuals and groups, telephone calls, face-toface interactions through parent/teacher conferences, home visits, back-to-school nights and open houses are important. Making communication as personal as possible increases effectiveness. They believe what parents do to help children learn is critical to academic success. Therefore, parents must be taught how to help children at home with materials provided by the school. Participation in school events and activities increases parental knowledge of the school and transmits the value of learning to children. 


\section{$\underline{\text { Parent Involvement Strategies }}$}

Although research indicates that family involvement significantly contributes to student learning and school success, it is difficult to identify effective strategies that meaningfully involve families in their children's education for rural, suburban, and urban settings (Henderson \& Berla, 1994; Swap, 1993; Kellaghan, Sloane, Alvarez \& Bloom, 1993). It appears that strategies must uniquely fit each community and also meet family variations. The greatest challenge to effective involvement is the ability to translate what research has documented into successful local programs.

A crucial parent involvement strategy is to help parents know what to do to enable their children's academic success. Research has documented that what families do to help children succeed in school is more important than the family's socio-economic status, cultural background, or parents' educational level (Kellaghan, Sloane, Alvarez, \& Bloom, 1993; McCarthey, 2000). The reality is that parents often do not know what is expected of them or how best to help. Some families need more help than others in learning to appreciate that they have a key role to play in their children's learning. Other families need little assistance in this area but need information regarding specific tasks in order to be involved as key players in children's academic success.

Another key parent involvement strategy is planning for needs resulting from changing demographics. At a time when schools are under increasing pressure to raise academic standards for all children, demographic changes are making school and home relationships more difficult. Major changes are more mothers in the work force, more single-parent homes, higher poverty rates, and differences between backgrounds of 
children and families and the adults who are working in schools. These changing demographics of communities produce stress between various cultures and backgrounds of school personnel and families. Complications include language and cultural barriers, reduced availability of caregivers to the school setting, limited time and resources for collaboration and family/community interactions (Riehl, 2000; Heymann \& Earle, 2000).

Swap (1993) contends families need many and varied opportunities for informal contacts with the school. Gatherings that provide family and school personnel opportunities for informal conversations help in building trust and respect. This enables the establishment of relationships for the mutual benefit of children. Positive relationships between the home and school reduce stress on children and help them to navigate the differences between the home and school. This results in greater academic success.

An important strategy that facilitates positive family involvement is the identification and removal of barriers to participation. These barriers are unique to the particular school environment but often involve such concerns as lack of time, feelings of inadequacy, feeling unwelcome in the school, not knowing how to use talents to help the school, lack of understanding of the school system, lack of adequate resources to meet basic needs, lack of child care, language barriers, and special needs due to disabilities, and lack of transportation (National PTA, 2000).

While the scope of needs may be overwhelming, solutions are possible. Through formal needs assessment processes and informal processes such as interactions and observations of families and children, barriers can be removed. Schools can connect with 
community resources and agencies that can assist with identified needs and barriers. The commitment to removal of barriers to participation is a direct indication of a school's commitment to full family engagement.

A strategy that is gaining acceptance is joint decision-making and advocacy. Many initiatives such as involvement of parents in Individualized Educational Program (IEP) meetings and as advisory boards for federal and state programs have existed for years, but there is a push for increasing direct involvement by parents and community members (Davies, 2001). Epstein (1995) describes these expanded parent involvement strategies as including parent leaders from all groups in school discussions, training for parent leaders who serve as representatives of other families and who deliver information to families, including students and parents in decision-making groups, creating and fostering collaborative activities with the community, informing families of community programs and opportunities, and the integrating family and child services with education.

Davies (2001) defines two purposes for family involvement in school decisionmaking. He contends that participation by parents in advocacy and decision-making impacts school reform by enabling students' academic success and provides opportunities for parents to acquire and practice democratic ideals. Swap (1993) contends that the collaborative process of making decisions may be as important as the actual activities and programs that are developed. The establishment of collaborative efforts such as school councils and other advocacy groups can be controversial and time-consuming. However, if parents are to become full partners in the educational process, consideration must be 
given to more inclusive types of activities. The dilemma is how best to structure and combine the efforts of schools, families, and communities for the benefit of students. In a number of states, a clear example of increased participation for schools, families, and communities is mandatory public school councils. These councils are designed to include community, family, and staff members in advocacy and decisionmaking. The exact structure is dictated by state law and thus varies considerably from state to state. In Kentucky, for example, school councils have significant authority including the selection of the school's principal (Davies, 2001). In Georgia, these councils are mandated by law to include the school principal, two teachers at the school, two parents of children at the school, and two businesspersons and are viewed as advisory groups to the schools and boards of education (Georgia School Council Institute, 2000).

Success in family partnerships results from commitment of educators, parents, and community members in a culture that supports collaboration. District, state, and national policies create contexts that influence actions, but it is unlikely that mandates are sufficient for success. The key to success is effective leadership from educators and community members (Swap, 1993).

One of the most important strategies involves the creation of a warm, inviting school atmosphere for children, parents, and community members. Such an atmosphere sets the tone for the development of quality relationships that lead to children's success in schools (Haynes, Comer, \& Hamilton-Lee, 1989). The establishment of effective relationships among and between all constituents of the school helps foster a more 
inclusive atmosphere and aids in understanding of the individual and cultural differences that exists (Riehl, 2000). In other words, the atmosphere of the school including such factors as the way adults respond to other adults, the way adults respond to children, and the physical appearance of the school all contribute to the groundwork for the establishment of full family and community engagement. The atmosphere of the school enables educators to fulfill their key role in reaching out to parents, students, and community members.

If effective partnerships are to become an integral part of the educational process for students, an essential parent involvement strategy is for educators to have extensive preparation and ongoing professional development in how to establish and maintain school, family, and community partnerships (Kirschenbaum, 2001). There must be funding and infrastructure to support partnership practices. This includes provisions such as time for educators to work with families, translators to facilitate parent-teacher conferences when language barriers exist, telephones in classrooms to enable teacherparent communication, technological advances such as web-based programs to inform parents, homework hotlines, and physical space for parent-teacher conferences. Commitment from the district and state level for the support of family involvement efforts is critical.

While there is evidence that a number of institutions are including instruction in partnership practices in educational training, only a limited number of higher institutions are providing comprehensive programs in school, family, and community relations. An 
extensive study at Harvard University sites the dismal amount of training for educators in partnerships (Kirschenbaum, 2001).

Epstein (1995) defines the need for pre-service and advanced degree programs for teachers and administrators that build the capacity for establishing and sustaining partnerships. Strategies should be emphasized that help educators effectively work with various cultures and diversity in family structures. Theory, research, and information about practical programs for family and community engagement should be priorities. The success of institutional efforts must be closely monitored for effectiveness.

A key strategy for the success of partnerships rests squarely on the acceptance that the role of teachers includes working with families as well as teaching in classrooms. Advocates of comprehensive partnerships between the home, school, and community view this expanded role for teachers as critical to the success of students' academic achievement and social development. Pre-service teachers as well as practicing teachers need courses and experiences that are designed specifically for enabling effective and practical ways of reaching out to families.

Principals must take active, leading roles in family involvement. They have key roles in promoting community partnerships and making thoughtful decisions that reflect the needs of children and families. Principals, as well as other school leaders, demonstrate that family involvement is a high priority by providing time, resources and opportunities for training (Swap, 2003).

Davies (2000) explains the role of principals as involving three areas. These include encouraging reciprocity among family, school and community constituents by 
providing mutual help in both formal and informal structures, the establishment of democratic processes so that varying constituents and their ideas are heard, and providing a variety of opportunities such as parent education, a wealth of communication, and other strategies that enable children's learning at home and in the community.

Communication with the home is an essential parent involvement strategy. It is established by many and varied positive contacts with the school in both formal and informal settings. A specific type of communication that warrants attention is teacher communication with the home. Numerous studies have shown that teacher communication with the home can increase other forms of parental involvement (Watkins, 1997).

The goal of two-way communication between the home and school is to establish a rich exchange of information between parents and educators (Swap, 1993). In recognition of the importance of this continuous flow of communication between parents and the school, the National PTA defined communication as their first of six standards for Parent/Family Involvement Programs. The PTA views communication as the essential foundation on which the other standards (parenting, student learning, volunteering, school decision-making and advocacy, and collaborating with the community) are built (National PTA, 2000).

Hiatt-Michael (2001) believes that educators have the responsibility to reach out in various ways to families and establish effective communication. This reduces stress on the child and establishes a very important means to know the child well. If the focus of 
education is the child's academic and social development then communication between the home and school is critical to the child's success. A continuous flow of information helps the child to see teachers and parents as working side-by-side. The child is very likely to have a more positive attitude towards school and learning.

A rich exchange of communication with the home includes informal, lessstructured contacts in addition to traditional exchanges such as parent orientation. Weiss et al. (1998) refers to these informal or targeted contacts as alternative communication patterns. The value of these exchanges is that parents and teachers learn valuable information that guides decisions about children. Examples of these interactions include discussions with a child's sibling, utilization of other school personnel for information (counselor, principal, reading specialist), unscheduled phone communications, conversations with extended family members working in the school, and informal chats between school personnel and parents at school arrival or dismissal times. Inherent in this type of communication is the establishment of trust between the home and school and accessibility of the family and the school.

The most effective roles for parents are unique to the school's situation and the needs and circumstances of the school, community, and families. Comprehensive needs assessments provide guidance for the establishment of a practical, effective system for family involvement. The system must work for the families involved and the information to families should lead to empowerment. Families must be helped to know what to do in the home, school, and community in order to enable children to succeed. 
The challenge for educators is to provide an atmosphere of mutual trust and respect between the home and school so that families and schools can fully engage as active participants in children's education. This reciprocal relationship provides the framework for a multitude of varied opportunities and informative exchanges designed to enable children's success. It provides families with opportunities for extensive involvement including parenting, communicating, volunteering, learning at home, decision-making, and collaborating with the community (Epstein, et al., 1997).

\section{$\underline{\text { School Reform Initiatives }}$}

Increasing family and community involvement is recognized as an important priority in many school reform initiatives. Breakthroughs are emerging that provide guidance to the development of partnerships that reach out to families and positively affect the success of children's learning and progress in school. However, the success is not widespread and is not translated into programs that are implemented with commitment and creativity (Drake, 2000). Programs that fully engage families are the exception despite the evidence and need for partnership (Swap, 1993).

Over thirty years ago, James Comer combined his knowledge of child psychiatry with education and emphasized the affective components of a child's development as directly impacting children's academic achievement (Comer, 1988). He believed that schools must not focus entirely on academics but also must focus on the relationships that students need to grow and learn. Comer's School Development Program (SDP) includes schools that provide strong, positive relationships among children, parents, and educators 
(Swap, 1993). These strong connections among all constituents are designed for the purpose of helping children learn. From SDP's beginning in New Haven, Connecticut in 1968, Comer's ideas have spread to other cities and states. Recently, the Rockefeller Foundation pledged three million dollars annually for five years to facilitate dissemination of Comer's program (National PTA, 2000).

Epstein et al. (1997) developed a comprehensive reform program. This program provides specific information on how to develop partnerships at the state, district, and school levels. The theory of overlapping spheres of influence emphasizing the shared responsibilities of the home, school, and community provides the foundation for action teams to develop involvement in parenting, communicating, volunteering, learning at home, decision making, and collaborating with the community. Schools, districts, and states that agree to required components can join the National Network of Partnership 2000 Schools established by researchers at Johns Hopkins University. Membership provides resources including workshops, newsletters, and many opportunities to share best practices and challenges.

The National Parent Teacher Association (PTA), in existence for over one hundred years, has a long history of affirming the significance of family/school partnerships. The organization disseminates information to a wide audience and exerts influence over national education policy. In 1997, based on the research of Joyce Epstein, the National PTA developed its National Standards for Parent/Family Involvement Programs. The organization believes that a synergistic effect results when the six types of involvement or standards (communicating, parenting, student learning, volunteering, 
school decision-making and advocacy, and collaborating with the community) are implemented simultaneously (National PTA, 2000).

The federal law, No Child Left Behind Act (2001), is the reauthorized Elementary and Secondary Education Act (ESEA). This federal law which affects K-12 education includes provisions for accountability, research-based instructional opportunities for students, expanded local control and flexibility, and expanded options for parents regarding their children's education. These rights for parents are far-reaching and indicate that the intent of the law is that parents are full partners in their children's education. These include the right to transfer their child to another school if the school does not meet state standards for at least two consecutive years and the provision for instructional support services for their child if the school does not meet state standards for at least three years. The programs and activities of the school and district are to be planned and implemented with input from the parents of the participating children. Specific provisions include a written parent involvement policy that is annually evaluated in conjunction with parents. An important component of the parent involvement structure is the development of a compact that incorporates shared responsibility with the parent, child, and school for high achievement (Henderson \& Mapp, 2002).

Evidence abounds that parental involvement is recognized and promoted as extremely important for the education of children. One of the eight goals in the 1994 Goals 2000 legislation includes the promotion of partnerships to enable the social, emotional, and academic growth of children (U. S. Department of Education, 1994). The National Board of Professional Teaching Standards explicitly addresses the need for 
teachers to work collaboratively with families (National Board, 2001). This need is emphasized by the Interstate School Leaders Licensure Consortium (Interstate School Leaders, 1996) as an integral part of school leadership. Strong agreement exists for the importance of family involvement. Policies, standards, and directives abound but family engagement is not fully realized through extensive, quality programs.

\section{Summary of Related Literature}

The evidence is convincing. Families contribute significantly to children's achievement in school and their success in life. When families work closely with their children's school, children do better in school and stay in school longer, the school as a whole improves, and children achieve at higher levels.

Partnerships provide opportunities for schools, families, and communities to work together to meet the needs of children. Schools are reflections of their communities and are dependent on them for resources and guidance. There is a need to build these supportive links and establish sustained mutual cooperation and collaboration.

Because schools are under increasing pressure to educate all children to higher standards, there is a need to enhance and improve partnerships. There is a long tradition in the United States of trying to involve parents. The challenge now is how to create new, positive relationships among schools, families, and communities. As financial resources for education decrease and expectations increase, partnerships offer possibilities for producing greater benefits for students. 
Conceptual frameworks are helpful for developing school-wide partnerships that really work. Key considerations include: establishing trust and respect among parents, school personnel, and the community; providing ongoing, positive communication; furnishing information about how to help children with academics at home; providing both formal and informal opportunities to meet with school personnel; creating opportunities for parents to meaningfully participate at school; and establishing a warm, inviting school atmosphere.

The challenge is to use these basic considerations for partnerships to guide specific local partnerships. A thorough, on-going needs assessment is helpful in guiding this effort. Information can be obtained through both formal needs assessment and through informal means such as observation of children and families. Strategies that support partnerships include: providing help to parents based on the needs of the child and the family; planning for needs resulting from changing demographics such as the use of translators; acknowledging and planning for barriers to parent participation such as lack of childcare, lack of transportation, lack of time to meet with school personnel; planning for joint decision making and advocacy such as school councils and collective participation; establishing an inclusive atmosphere that enables understanding of individual and cultural differences and that enables educators to fulfill their roles in reaching out to parents and community members; providing professional development for teachers and school leaders and monitoring effectiveness of outcomes; emphasizing that the role of teachers and educational leaders is vital to the success of partnerships and that 
time must be given for them to perform these duties; and communicating with the home utilizing multitude resources in order to establish on-going, positive exchanges.

The recent No Child Left Behind Act (2001) is exerting pressure on schools to increase parental involvement. This law includes school choice for parents and mandates involvement in program decisions.

Parental involvement is recognized and promoted as extremely important for the education of students. However, the authentic engagement of parents is not a reality. The establishment of effective partnerships is elusive. Parents, educators, and community members need to make a strong commitment to work together, provide resources, and expend time. Partnerships can be established that help schools and students succeed and prosper. 


\section{CHAPTER III \\ METHODS AND PROCEDURES}

\section{$\underline{\text { Research Design }}$}

This study investigated the School-Home Partnership Model at Metter Intermediate School, a small rural elementary school in southeast Georgia. The school served an economically depressed population. Subjects included two hundred eighty students in grades four and five, their parents, and the teachers of the school.

Documents were examined for the purpose of investigating students' report card grades, student attendance records, standardized test scores, behavioral referrals to the school office, and parent/staff participation in school events. Parents, students, and teachers were surveyed to gain insight into feelings, beliefs and behaviors toward the school (Dillman, 1978). Teachers at the school served as key informants (Yin, 1994). Emphasis was given to the impact of the School-Home Partnership Model on "at-risk" students in particular.

Two hundred eighty students, their parents, and seventeen teachers participated as subjects in the study. Of the two hundred eighty students, approximately 125 students were identified as "at-risk" based on membership in Georgia's Early Intervention Program and/or identified as special education students based on the Individuals with 
Disabilities Education Act (IDEA). The term "at-risk" student was defined to mean a student identified as being below grade level in reading and/or math based on the guidelines of Georgia's Early Intervention Program (EIP). The term also meant students identified as a special education student according to the Individuals with Disabilities Education Act (IDEA). Since "at-risk" students are generally students who are in danger of not completing their education with an adequate level of skills, it was important to investigate the impact of the School-Home Partnership Model on this group of students.

Teachers included twelve regular education teachers who taught both "at-risk" and non "at-risk" students, one teacher who taught exclusively Early Intervention Program students, two teachers who taught exclusively special education students, and one staff member who taught gifted students and served as the school counselor.

This study investigated the impact of the School-Home Partnership Model created for Metter Intermediate School that was used from fall 2001 to spring 2004 in relation to nine specific items:

1. Student scores on the Georgia Criterion-Referenced Tests (Georgia Department of Education, 1999).

2. Student grades on report cards in four key academic areas: English, reading, spelling, and mathematics.

3. Student daily attendance at school.

4. Student behavior in relation to discipline referrals to the school office.

5. Parent and staff participation in parent-teacher meetings.

6. Parent participation in school activities and events.

7. Student perceptions of the school. 
8. Teacher perceptions of the school.

9. Parent perceptions of the school.

The Institutional Review Board at Mississippi State University granted permission for the researcher to conduct the study. The superintendent of the school district gave written consent for the study to be conducted (Appendix A).

\section{Document Examination}

Documents were reviewed to investigate the responses of students, parents, and teachers. In the following paragraphs, these documents and methods of evaluation are explained.

Students' report card grades for fifth grade students (2003-2004) were compared for two years. Final grades for fifth graders in reading, English, spelling, and math were compared to their final grades as fourth graders. These students experienced the SchoolHome Partnership Model for two years. Descriptive statistics were utilized to determine possible changes.

Report card grades in reading, English, spelling, and math for fourth grade students (2003-2004) were compared utilizing first semester grades and second semester grades. These students experienced the School-Home Partnership Model for one year. Descriptive statistics were utilized to determine possible changes.

Student attendance records for fifth grade students (2003-2004) were compared for two years. This yearly attendance data were analyzed using descriptive statistics. These students experienced the School-Home Partnership Model for two years. 
Student attendance data for fourth grade students (2003-2004) were insufficient for analysis.

Student behavioral referrals to the school office for fifth graders (2003-2004) were compared for the two years they experienced the School-Home Partnership Model. Descriptive statistics were used to describe possible changes by years. For fourth graders (2003-2004), the number of student behavioral referrals to the school office was analyzed by semesters using descriptive statistics.

Scores on the Georgia Criterion Referenced Competency Test (CRCT) were analyzed for three years for fifth graders (2003-2004). This test was used to measure student achievement in relation to the required Georgia curriculum (Georgia Department of Education, 1999). The reading and math scores of fifth graders from spring 2002, spring 2003, and spring 2004 were used. The researcher used $t$ tests with an alpha level set at .05 to determine if the changes in scores were statistically significant. (No analysis was done for fourth graders because only one set of CRCT scores was available.)

The purpose of the $t$ test is to compare the actual mean differences observed with the mean differences that would be expected by chance. Thus, the t-ratio determines whether observed differences are sufficiently larger than differences that would be expected by chance. Based on the probability level and the degrees of freedom, the calculated $t$ value is compared to the appropriate $t$ table value. If the calculated $t$ value is greater or equal to the table value, the null hypothesis is rejected indicating there is a statistically significant difference in mean scores (Gravetter \& Wallnau, 2000). 
The participation of parents and staff in school events was reviewed and analyzed for changes, if any. Extensive, thorough records were not available.

\section{Teacher Perceptions of the School-Home Partnership Model}

Teachers were surveyed to investigate their perceptions toward the School-Home Partnership Model (Appendix B). Participation in the survey was voluntary. Two copies of a consent form (Appendix C) were given to each teacher in the school requesting that he/she participate in the study by completing a survey. Teachers were told to keep one copy for their records and to return the signed consent to the researcher at the school. After receiving a signed consent from the teacher, a survey was given to the teacher by the researcher. The teacher was provided with an addressed, stamped envelope in order to mail it to the researcher.

A four-point measurement scale was used for the eighteen close-ended items on the survey. Participants were asked to "strongly disagree," "disagree," "agree," or "strongly agree" to each of the items on the instrument. Chi-square for goodness of fit test was used to determine whether the frequency of distribution showed a specific pattern. Each category could be expected to be selected with equal frequency if there were no preferences. Although observed frequencies will almost always differ somewhat from expected frequencies, the pertinent question asked in analyzing data collected by the instrument was as follows: Are the differences significant or are they due to chance? An alpha level of .01 was selected to determine if participants' responses were statistically significant. 
The instrument also included two open-ended statements addressing parental involvement at the school. Responses to the instrument's open-ended questions were analyzed for the purpose of identifying patterns.

\section{Student Perceptions of the School-Home Partnership Model}

Students were surveyed to investigate their perceptions toward the model.

(Appendix D, Appendix E). Students carried two copies of a consent form home to their parents requesting permission to participate in the survey (Appendix F). Parents were instructed to keep a copy for their records and to return a signed copy to the researcher. Additionally, the students who obtained permission from their parents signed written assents before completing the survey (Appendix G).

Since the researcher wanted to compare the impact of the parent involvement model on "at-risk" students to non "at-risk" students, placing an identifier for student surveys for "at-risk" students ensured confidentiality. This was accomplished by a difference in the placement of one word on the student survey. On the surveys for "atrisk" students, the word "about" was located on the second line of the instructions for the survey. On the surveys for the non "at-risk" students, the word "about" was at the end of the first line of the instructions on the survey. The purpose of the identifier was to delineate for the researcher the responses of "at-risk" students and non "at-risk" students. It likely was beneficial to compare the results of reactions to the School-Home Partnership Model from "at-risk" students and non "at-risk" students. (For explanation of "at-risk" students see section titled Research Design in this chapter.) 
Prior to administering the survey to those students whose parents gave consent, the researcher placed the name of each child on a survey by using a sticky note. "At-risk" students received a survey (Appendix D) and non "at-risk" students received a survey (Appendix E). As surveys were distributed, the researcher removed each sticky note as each child was given a survey. When completed, each child placed his/her survey in a sealed envelope and gave it to the researcher.

A four-point measurement scale was used for the twelve close-ended items. Students were asked to "strongly disagree," "disagree," "agree," or "strongly agree" to each of the items on the instrument. As outlined above for the teacher surveys, chisquare for goodness of fit test was used to determine whether the frequency of distribution showed a specific pattern. An alpha level of .01 was selected to determine if students' responses were statistically significant. The instrument also included one openended item.

\section{Parent Perceptions of the School-Home Partnership Model}

Parents were surveyed to investigate their perceptions toward the model. All students in the school carried home two copies of a consent form (Appendix F) requesting parent permission for the researcher to mail them a survey about the school. The parents were asked to keep one copy of the consent form for their records and to return a signed consent form to the researcher. The researcher then mailed parent surveys to those who had consented. Stamped, self-addressed envelopes were provided in order for the parents to return the surveys to the researcher. 
Since the researcher wanted to compare the impact of the parent involvement model on "at-risk" students and their parents to non "at-risk" students and their parents, confidentiality was ensured. An identifier was used for the parent surveys for "at-risk" students. This was accomplished by a difference in the placement of one word on the parent survey. On the surveys for parents of "at-risk" students, the word "about" was located on the second line of the instructions for the survey (Appendix H). On the surveys for parents of non "at-risk" students the word "about" was at the end of the first line of the instructions for the survey (Appendix I). The purpose of the identifier was to delineate for the researcher the responses of parents of "at-risk" students and parents of non "at-risk" students. It was likely beneficial to compare the results of reactions of the School-Home Partnership Model for parents of "at-risk" students and parents of non "atrisk" students. (For explanation of "at-risk" students see section titled Research Design in this chapter.)

The parent survey contained twenty close-ended items. Parents were asked to "strongly disagree," "disagree," "agree," or "strongly agree" to each of the items on the instrument. As outlined above for the teacher and student surveys, chi-square for goodness of fit test was used to determine whether the frequency of distribution showed a specific pattern. An alpha level of .01 was selected to determine if parents' responses were statistically significant. Additionally, the parent survey contained two open-ended responses. 


\section{$\underline{\text { Key Informants }}$}

To further gain understanding of the School-Home Partnership Model, teachers served as key informants. Each teacher in the school was given two copies of a consent form (Appendix J) requesting an interview with the researcher. The teacher kept one copy of the consent form for his/her records and signed and returned one copy to the researcher. Interviews took place at the school during the month of May and June 2004 at a convenient time for each teacher. Ten questions guided the interviews with teachers:

1. How are parents involved at our school?

2. What are the best ways to keep parents informed about their child's progress in school?

3. In what ways do you communicate with parents? Which ways are the most effective?

4. What strategies do you use to get to know your students and their parents?

5. Do you ever invite parents to come to school? If yes, tell some of the reasons you have invited them. What were the results?

6. What is the role of the teacher in home-school communication?

7. How could our school increase parent participation in children's education? What differences, if any, are there between involving parents of "at-risk" students (special education or Early Intervention Program students) and non "at-risk" students?

8. Do you give any specific help to parents in order for them to assist their child with academics? If so, please explain.

9. What are the advantages/disadvantages of our school agendas? How can we use them more effectively? 
10. Is there anything else you would like to say about our school? What can we do to improve home-school communication, student behavior, and academic success?

Responses were recorded by audiotape, but no identifiable responses were used. In the text of Chapter IV, individual teachers were identified as T1, T2, etc. and responses were aggregated to create an overall profile. 


\section{CHAPTER IV \\ FINDINGS AND DISCUSSION}

This study investigated the School-Home Partnership Model at Metter Intermediate School, a small rural elementary school. The school, located in southeast Georgia, served an enrollment of two hundred eighty students in grades four and five. The economically depressed population consists of fifty percent white (non Hispanic), thirty-eight percent Black, ten percent Hispanic, and two percent classified as "other".

Metter Intermediate School administrators created the School-Home Partnership Model in 2001 for the purpose of increasing the involvement of families in their children's education in order to improve academic achievement and behavior.

The impact of this model was studied in relation to nine specific items:

1. Student scores on the Georgia Criterion-Referenced Tests (CRCT).

2. Student grades on report cards in four key academic areas: English, reading, spelling, and mathematics.

3. Student daily attendance at school.

4. Student behavior in relation to discipline referrals to the school office.

5. Parent and staff participation in parent-teacher meetings.

6. Parent participation in school activities and events.

7. Teacher perceptions of the school. 
8. Student perceptions of the school.

9. Parent perceptions of the school.

The study also investigated the impact of the School-Home Partnership Model on "at-risk" students in particular. Approximately thirty-seven percent of the students were in the Early Intervention Program. This meant that this population was below grade level performance in reading and/or math. Ten percent of the students were identified as special education students and seven percent were identified as gifted. During the 20022003 school year, seventy-eight percent of the students were eligible for free and reduced meals.

For the purpose of this study the term "at-risk" student was defined to mean a student identified as being below grade level in reading and/or math based on the guidelines of Georgia's Early Intervention Program (EIP). The term "at-risk" student as used in this study also meant a student identified as a special education student according to the Individuals with Disabilities Education Act (IDEA). An "at-risk" student was generally a student who was in danger of not completing his or her education with an adequate level of skills. Common risk factors were grade retention, low achievement, behavior problems, low socioeconomic status, and poor attendance (Slavin, 1989).

This chapter presents and discusses the study's findings. Quantitative methods and interviews were utilized to collect, analyze, and interpret data. Techniques included document review, interviews, and attitudinal surveys.

The findings are organized into five sections. Results are presented in (a) document analysis of report card grades, student attendance records, student scores on the 
Criterion-Referenced Competency Tests (Georgia Department of Education, 1999), behavioral referrals to the school office, and parent/staff participation records, (b) teacher perceptions of the School-Home Partnership Model, (c) student perceptions of the School-Home Partnership Model, (d) parent perceptions of the School-Home Partnership Model, and (e) key informant interviews.

\section{Document Analysis}

\section{$\underline{\text { Report Card Grades }}$}

Utilizing descriptive statistics, students' report card grades for the fifth grade students (2003-2004) were analyzed for two years. Final grades for these fifth graders in reading, English, spelling, and math were compared to their final grades as fourth graders. These students experienced the School-Home Partnership Model for two years.

Table 1 summarizes students' grades into non "at-risk" students and "at-risk" students. For the non "at-risk" students, the end of the year mean in reading dropped from $\mathrm{M}=90.07, \mathrm{SD}=5.64$ in 2003 to $\mathrm{M}=88.99, \mathrm{SD}=6.63$ in 2004 , a decrease of 1.08 points. Also the end of the year mean in English dropped from $M=90.44, S D=6.87$ in 2003 to $M=89.01, S D=6.84$ in 2004 , a decrease of 1.43 points. The means in spelling and math showed small decreases.

For the "at-risk" students, the mean at the end of the year in spelling increased from $M=84.13, S D=8.80$ in 2003 to $M=86.40, S D=8.65$ in 2004 , an increase of 2.27 points. An increase was also shown in math with $\mathrm{M}=80.17, \mathrm{SD}=4.41$ in 2003 to 
$M=84.03, S D=8.08$ in 2004 , a gain of 3.86 points. The mean in reading decreased by 1.47 points from $M=84.70, S D=5.46$ in 2003 to $M=83.23, S D=6.84$ in 2004 . Also, the end of year mean in English $(M=83.60, S D 6.31$ in 2003) to $M=82.43, S D=6.22$ in 2004 decreased 1.17 points.

\section{$\underline{\text { Table } 1}$}

Means \& Standard Deviations for Report Card Grades by Years for Risk Groups

\begin{tabular}{|c|c|c|c|c|}
\hline & Non At & udents & & Students \\
\hline & $\underline{2003}$ & 2004 & 2003 & 2004 \\
\hline Reading & $M=90.07$ & $M=88.99$ & $M=84.70$ & $M=83.23$ \\
\hline & $\mathrm{SD}=5.64$ & $\mathrm{SD}=6.63$ & $\mathrm{SD}=5.46$ & $\mathrm{SD}=6.84$ \\
\hline English & $M=90.44$ & $M=89.01$ & $M=83.60$ & $M=82.43$ \\
\hline & $\mathrm{SD}=6.87$ & $\mathrm{SD}=6.84$ & $\mathrm{SD}=6.31$ & $\mathrm{SD}=6.22$ \\
\hline Spelling & $M=92.44$ & $M=92.04$ & $\mathrm{M}=84.13$ & $\mathrm{M}=86.40$ \\
\hline & $\mathrm{SD}=7.02$ & $\mathrm{SD}=7.38$ & $\mathrm{SD}=8.80$ & $\mathrm{SD}=8.65$ \\
\hline Math & $\mathrm{M}=88.39$ & $M=89.32$ & $M=80.17$ & $M=84.03$ \\
\hline & $\mathrm{SD}=7.54$ & $\mathrm{SD}=7.01$ & $\mathrm{SD}=4.41$ & $\mathrm{SD}=8.08$ \\
\hline
\end{tabular}

$\mathrm{n}($ Non At Risk $)=72$

$\mathrm{n}$ (At Risk) $=30$

Table 2 summarizes the fifth grade students' grades for the total class (both risk groups). The most notable change was in math $\mathrm{M}=86.33, \mathrm{SD}=7.73$ to $\mathrm{M}=88.05$, $\mathrm{SD}=7.54$, an increase of 1.72 points. Reading and English means dropped by 1.00 and 1.14 , respectively. Spelling changed by less than one point. 
$\underline{\text { Table } 2}$

Means \& Standard Deviations for Report Card Grades by Years for Total Class

\begin{tabular}{|c|c|c|}
\hline & 2003 & 2004 \\
\hline Reading & $\begin{array}{l}M=88.46 \\
S D=6.10\end{array}$ & $\begin{array}{l}\mathrm{M}=87.46 \\
\mathrm{SD}=7.20\end{array}$ \\
\hline English & $\begin{array}{l}M=88.59 \\
S D=7.38\end{array}$ & $\begin{array}{l}M=87.45 \\
S D=7.10\end{array}$ \\
\hline Spelling & $\begin{array}{l}M=90.15 \\
\mathrm{SD}=8.38\end{array}$ & $\begin{array}{l}M=90.56 \\
\mathrm{SD}=8.17\end{array}$ \\
\hline Math & $\begin{array}{l}M=86.33 \\
S D=7.73\end{array}$ & $\begin{array}{l}M=88.05 \\
S D=7.54\end{array}$ \\
\hline
\end{tabular}

$\overline{n-100}$

In summary, for the fifth grade class of 2003-2004, the two years of report card grades showed that the means for the non "at-risk" students grades declined in reading by 1.08 points $\mathrm{M}=90.07, \mathrm{SD}=5.64$ in 2003 to $\mathrm{M}=88.99, \mathrm{SD}=6.63$ in 2004 and in English by 1.43 points $(\mathrm{M}=90.44, \mathrm{SD}=6.87$ in 2003 to $\mathrm{M}=89.01, \mathrm{SD}=6.84$ in 2004). Improvements for "at-risk" students were noted in the means for spelling ( $M=84.13, S D=8.80$ in 2003 to $\mathrm{M}=86.40, \mathrm{SD}=8.65$ in 2004) and math $(\mathrm{M}=80.17, \mathrm{SD}=4.41$ in 2003 to $\mathrm{M}=84.03$, $\mathrm{SD}=8.08$ in 2004). For the class as a whole (both risk groups), math improved by 1.72 point $(\mathrm{M}=86.33, \mathrm{SD}=7.73$ in 2003 to $\mathrm{M}=88.05, \mathrm{SD}=7.54$ in 2004).

Table 3 shows the report card grades by semesters using descriptive statistics for the non "at-risk" and "at-risk" fourth graders in 2003-2004. Semester grades for these students were utilized in reading, English, spelling, and math. For the non "at-risk" students, the semester grades showed decreases in reading from $M=91.70, S D=4.20$ for the first semester to $\mathrm{M}=90.50, \mathrm{SD}=5.00$ for the second semester, a 1.20 decrease. Also, 
math decreased from $M=89.80, S D=5.60$ in the first semester to $M=88.40, S D=6.70$ in the second semester, a decrease of 1.40 points. Changes in means for English and Spelling were less than 1.0 point.

For the "at-risk" students, the reading grades increased from $\mathrm{M}=84.26, \mathrm{SD}=7.89$ in the first semester to $\mathrm{M}=87.55, \mathrm{SD}=4.30$ in the second semester. This resulted in a gain of 3.30 points. Also, the math grades increased from $M=79.90, S D=7.92$ in the first semester to $M=81.23, S D=5.83$ in the second semester. This resulted in a gain of 1.30 points. The change in the means for English was less than 1.0 point. In Spelling, the change in means was 1.10 points.

\section{$\underline{\text { Table } 3}$}

Means \& Standard Deviations for Report Card Grades by Semesters for Risk Groups

\begin{tabular}{lllll}
\hline & \multicolumn{2}{c}{ Non At Risk Students } & \multicolumn{2}{c}{ At Risk Students } \\
& \multicolumn{1}{c}{$1^{\text {st }}$ Semester } & $2^{\text {nd }}$ Semester & $1^{\text {st }}$ Semester & $2^{\text {nd }}$ Semester \\
\cline { 2 - 5 } Reading & $\mathrm{M}=91.7$ & $\mathrm{M}=90.50$ & $\mathrm{M}=84.26$ & $\mathrm{M}=87.55$ \\
& $\mathrm{SD}=4.20$ & $\mathrm{SD}=5.00$ & $\mathrm{SD}=7.89$ & $\mathrm{SD}=4.30$ \\
English & & & & \\
& $\mathrm{M}=93.30$ & $\mathrm{M}=92.50$ & $\mathrm{M}=82.28$ & $\mathrm{M}=82.15$ \\
Spelling & $\mathrm{SD}=3.20$ & $\mathrm{SD}=3.70$ & $\mathrm{SD}=8.67$ & $\mathrm{SD}=5.26$ \\
& & & & \\
Math & $\mathrm{M}=95.90$ & $\mathrm{M}=95.80$ & $\mathrm{M}=82.45$ & $\mathrm{M}=83.55$ \\
& $\mathrm{SD}=3.10$ & $\mathrm{SD}=3.20$ & $\mathrm{SD}=9.80$ & $\mathrm{SD}=8.30$ \\
& $\mathrm{M}=89.80$ & $\mathrm{M}=88.40$ & $\mathrm{M}=79.90$ & $\mathrm{M}=81.23$ \\
& $\mathrm{SD}=5.60$ & $\mathrm{SD}=6.70$ & $\mathrm{SD}=7.92$ & $\mathrm{SD}=5.83$ \\
\hline
\end{tabular}

$\mathrm{n}($ Non At Risk $)=33$

$\mathrm{n}($ At Risk $)=40$

Table 4 summarizes the fourth grade students' grades for the total class (both risk groups). The means of the reading scores increased from $M=87.60, S D=7.34$ in the first 
semester to $\mathrm{M}=88.75, \mathrm{SD}=4.90$ in the second semester, an increase of 1.15 points. Other mean scores were virtually the same.

Table 4

Means \& Standard Deviations for Report Card Grades by Semesters for Total Class

\begin{tabular}{lll}
\hline \multirow{2}{*}{ Reading } & $1^{\text {st }}$ Semester & $2^{\text {nd }}$ Semester \\
\cline { 2 - 3 } English & $\mathrm{M}=87.60$ & $\mathrm{M}=88.75$ \\
& $\mathrm{SD}=7.34$ & $\mathrm{SD}=4.90$ \\
Spelling & $\mathrm{M}=87.28$ & $\mathrm{M}=86.74$ \\
& $\mathrm{SD}=8.57$ & $\mathrm{SD}=6.94$ \\
Math & $\mathrm{M}=88.51$ & $\mathrm{M}=88.87$ \\
& $\mathrm{SD}=9.96$ & $\mathrm{SD}=8.90$ \\
& $\mathrm{M}=84.28$ & $\mathrm{M}=84.15$ \\
\hline
\end{tabular}

$\mathrm{n}=75$

In summary, the non "at risk" students in the fourth grade class of 2003-2004 obtained semester grades which showed slight decreases in mean scores for reading and math. For "at-risk" students it was noteworthy that reading increased by 3.30 points. Math for "at-risk" students increased by 1.30 points. For the class as a whole (both risk groups), only slight changes were evident.

\section{$\underline{\text { Student Attendance Records }}$}

Descriptive statistics were used to analyze the number of days absent from school (based on 180 days per school year). Attendance data for the fifth grade class from 20032004 were reviewed for the 2002-2003 and 2003-2004 school years. 
Table 5 displays the means and standard deviations for the non "at-risk" students and the "at-risk" students. Both of these groups had decreases in the number of days absent. For the non "at-risk" students the number of days absent decreased from $M=4.52$, $\mathrm{SD}=4.37$ for 2003 to $\mathrm{M}=4.29, \mathrm{SD}=4.73$ for 2004 , a decrease in the difference of the means of 0.23 . The "at-risk" group's yearly absences decreased from $\mathrm{M}=5.62, \mathrm{SD}=6.69$ in 2003 to $\mathrm{M}=5.32, \mathrm{SD}=4.37$ in 2004 , a decrease in the difference of the means of 0.30 .

\section{$\underline{\text { Table } 5}$}

Means \& Standard Deviations for Days Absent by Years for Risk Groups

\begin{tabular}{lrrrr}
\hline & \multicolumn{2}{c}{ Non At Risk } & \multicolumn{2}{c}{ At Risk } \\
& 2003 & 2004 & 2003 & 2004 \\
\cline { 2 - 5 } Mean & & & & 5.62 \\
Standard Deviation & 4.52 & 4.29 & 6.69 & 5.32 \\
\hline
\end{tabular}

n $($ Non At Risk $)=63$

$\mathrm{n}($ At Risk $)=21$

Table 6 displays the number of days absent from school (based on 180 days per school year) for the total class (both risk groups). As with each risk group, the total group decreased slightly, a 0.25 difference in means, from $2003(\mathrm{M}=4.80, \mathrm{SD}=5.03)$ to $2004(\mathrm{M}=4.55, \mathrm{SD}=4.64)$.

Table 6

Means \& Standard Deviations for Days Absent by Years for Total Class

\begin{tabular}{lcc}
\hline & 2003 & 2004 \\
Mean & 4.80 & 4.55 \\
Standard Deviation & 5.03 & 4.64 \\
\hline $\mathrm{n}=84$ & &
\end{tabular}

$\mathrm{n}=84$ 


\section{Criterion-Referenced Competency Tests (CRCT)}

The Georgia Criterion-Referenced Competency Tests (CRCT) were used to measure how well students acquired the skills and knowledge in relation to the required Georgia curriculum (Georgia Department of Education, 1999). The reading and math scores for students who experienced the School-Home Partnership Model for two years were analyzed. Scores for the 2003-2004 class of fifth graders in reading and math were available for spring, 2002, the year prior to entry into Metter Intermediate School and for spring, 2003 and spring, 2004. Paired t tests were used to determine whether changes in scores were statistically significant at an alpha level of .05 .

On the CRCT in reading, the means of two correlated samples were used to determine if statistically significant differences existed. When the scores for the non "atrisk" students for $2002(\mathrm{M}=354.55, \mathrm{SD}=33.55)$ were compared to the scores for 2003 $(\mathrm{M}=370.58, \mathrm{SD}=41.66), \mathrm{t}(52)=-4.129, \mathrm{p}<.05$ (two-tailed), a statistically significance difference was obtained. Thus, the non "at-risk" students scores in reading improved. However, the same non "at-risk" group of students decreased at a statistically significant level in reading from $2003(\mathrm{M}=370.58, \mathrm{SD}=41.66)$ to $2004(\mathrm{M}=354.89, \mathrm{SD}=35.06$, $t(52)=-4.047, p<.05$ (two-tailed). When the scores for the non "at-risk" students for 2002 $(M=354.29, S D=32.96)$ were compared to the scores for $2004(M=355.04, S D 34.42)$, $\mathrm{t}(54)=-.259, \mathrm{p}<.05$ (two-tailed), a statistically significant difference was not found. Thus, the improvement in reading scores in 2003 was not maintained in 2004.

Changes in CRCT reading scores were not statistically significant for the "at-risk" students for any of the two correlated samples. Results in $2002(\mathrm{M}=310.50, \mathrm{SD}=22.69)$ 
and $2003(\mathrm{M}=304.44, \mathrm{SD}=32.01), \mathrm{t}(17)=.847, \mathrm{p}<.05$ (two-tailed) showed no statistically significant differences. Likewise, correlated samples in $2003(M=297.28, S D=20.73)$ and $2004(\mathrm{M}=305.22, \mathrm{SD}=22.73), t(17)=-1.911, \mathrm{p}<.05$, (two-tailed), showed no statistically significant changes. Additionally, comparisons of correlated sample from 2002 $(\mathrm{M}=310.50, \mathrm{SD}=22.69)$ and $2004(\mathrm{M}=308.50, \mathrm{SD}=24.65), \mathrm{t}(17),=.330, \mathrm{p}<.05$ (twotailed), showed no statistically significant change.

On the CRCT in reading for the total 2003-2004 class of fifth graders (both risk groups), changes in scores between 2002 and 2003 were statistically significant. The scores for $2002(\mathrm{M}=343.13, \mathrm{SD}=36.72)$ and $2003(\mathrm{M}-354.24, \mathrm{SD}=48.96), \mathrm{t}(69)=-3.128$, $\mathrm{p}<.05$ (two-tailed) indicated a statistically significant difference in achievement. Thus, reading achievement as measured by the $\mathrm{CRCT}$ increased.

On the CRCT in math, the means of two correlated samples were used to determine if statistically significant changes in scores had occurred. For the non "at-risk" group of students no statistically significant differences were obtained. For 2002 $(\mathrm{M}=339.64, \mathrm{SD}=27.47)$ and $2003(\mathrm{M}=336.40, \mathrm{SD}=25.64), \mathrm{t}(52)=1.027, \mathrm{p}<.05$ (twotailed) the scores showed no statistically significant differences. Also, for 2002 $(M=339.64, S D=27.47)$ and $2004(M=340.21, S D=23.04), t(52)=-.191, p<.05$, (twotailed) no statistically significant differences were found.

For the "at-risk" students on CRCT in math, a statistically significant difference was found in $2002(\mathrm{M}=308.11, \mathrm{SD}=22.52)$ and $2003(\mathrm{M}=297.28$, $\mathrm{SD}=20.73), t(17)=2.906, \mathrm{p}<.05$, (two-tailed). Thus, these students' scores indicated a decrease in achievement. Comparisons of correlated samples for other years indicated 
no statistically significant differences. In $2002(\mathrm{M}=308.11, \mathrm{SD}=22.52)$ and 2004 $(\mathrm{M}=305.22, \mathrm{SD}=22.73), \mathrm{t}(17)=.895, \mathrm{p}<.05$, (two-tailed), showed no statistically significant difference. This was also the case with $2003(\mathrm{M}=297.28, \mathrm{SD}=20.73)$ and 2004( $\mathrm{M}=305.22, \mathrm{SD}=22.73), \mathrm{t}(17)=-1.911, \mathrm{p}<.05$, (two-tailed).

The total class of fourth graders (both risk groups) showed statistically significant changes in CRCT math scores from $2003(M=326.04, S D=29.83)$, to $2004(M=331.16$, $\mathrm{SD}=27.63), \mathrm{t}(69)=-2.530, \mathrm{p}<.05$, (two-tailed). This improvement in math CRCT followed a decrease noted by a statistically significant difference in $2002(\mathrm{M}=331.33, \mathrm{SD}=29.66)$ to $2003, \mathrm{M}=326.04, \mathrm{SD}=29.83, \mathrm{t}(69)=-2.086$.

In summary for CRCT scores for fifth graders in 2003-2004, the non "at-risk" students CRCT reading scores improved from 2002 to 2003, but declined from 2003 to 2004. For this same non "at-risk" group, CRCT math scores showed no statistically significant changes.

For the "at-risk" fifth graders in 2003-2004, the CRCT reading scores showed no statistically significant change. For CRCT math achievement decreased indicated by a statistically significant difference in scores from 2002 to 2003.

For the class as a whole (both risk groups), the CRCT reading scores showed a statistically significant difference (improvement) from 2002 to 2003. For CRCT math, a statistically significant difference was noted for 2002 to 2003 (decrease) and from 2003 to 2004 (increase). 


\section{Behavioral Referrals to the School Office}

Descriptive statistics were utilized to analyze student behavioral referrals to the school office. The number of referrals to the school office for the 2003-2003 and 2003-2004 school years was utilized for the fifth grade class of 2003-2004. Table 7 contains a summary of this information for the non "at-risk" students and for the "at-risk" students.

For the non "at-risk" students the mean increased 0.30 in $2004(\mathrm{M}=1.09$, $\mathrm{SD}=2.13)$ from $2003(\mathrm{M}=.79, \mathrm{SD}=.55)$. For "at-risk" students, the mean increased 0.99 in $2004(\mathrm{M}=1.26, \mathrm{SD}=2.12$ by 0.00 from $\mathrm{M}=27, \mathrm{SD}=0.75$ in 2003 .

\section{$\underline{\text { Table } 7}$}

Means \& Standard Deviations for Behavior Referrals by Years for Risk Groups

\begin{tabular}{lllll}
\hline & \multicolumn{2}{c}{ Non At Risk } & \multicolumn{2}{c}{ At Risk } \\
& 2003 & 2004 & 2003 & 2004 \\
\cline { 2 - 5 } Mean & & & & \\
Standard Deviation & 0.79 & 1.09 & 0.27 & 1.26 \\
\hline
\end{tabular}

$\mathrm{n}($ Non At Risk $)=67$

$\mathrm{n}($ At Risk $)=23$

Table 8 displays information for the total class (both risk groups). There was an increase of 0.10 in the mean for $2004(M=0.52, S D=1.31)$ from $M=0.42, S D=1.23$ in 2003. 
Table 8

Means \& Standard Deviations for Behavior Referrals by Years for Total Class

\begin{tabular}{lll}
\hline & 2003 & 2004 \\
& & \\
Mean & 0.42 & 0.52 \\
Standard Deviation & 1.23 & 1.31 \\
\hline $\mathrm{n}=90$ &
\end{tabular}

Overall, the number of behavioral referrals to the school office for the non "atrisk" students and for the class as a whole increased slightly $(0.30,0.10$ respectively). However, for the "at-risk" students, referrals increased by 0.99 .

Table 9 displays the behavioral referrals to the school office for the fourth grade class of 2003-2004. Yearly totals were not available for this group of students, so semester totals for one year were utilized. For the non "at-risk" students, there was a very slight decrease $(0.03)$ in the mean for the second semester $(M=0.26, S D=0.86)$ from the first semester $(\mathrm{M}=0.29, \mathrm{SD}=1.24)$. For the "at-risk" students, an increase $(0.82)$ in the second semester mean $(\mathrm{M}=0.82, \mathrm{SD}=1.51)$, resulted in a 0.21 difference from the first semester $(\mathrm{M}=0.61, \mathrm{SD}=1.47)$.

\section{Table 9}

Means \& Standard Deviations for Behavior Referrals by Semesters for Risk Groups

\begin{tabular}{llll}
\multicolumn{2}{c}{$\begin{array}{c}\text { Non At Risk Students } \\
\text { st }\end{array}$} & \multicolumn{2}{c}{ At Risk Students } \\
$1^{\text {st }}$ Semester & $2^{\text {nd }}$ Semester & & \\
& & $\mathrm{M}=0.61$ & $\mathrm{M}=0.82$ \\
$\mathrm{M}=0.29$ & $\mathrm{M}=0.26$ & $\mathrm{SD}=1.47$ & $\mathrm{SD}=1.51$
\end{tabular}

$\mathrm{n}($ Non At Risk $)=34$

$n$ (At Risk) $=44$ 
Table 10 displays the semester data for the total group (both risk groups) for fourth graders of 2003-2004. A slight increase (0.16) in the number of behavioral referrals to the school office is shown in the second semester $(\mathrm{M}=0.54, \mathrm{SD}=1.23)$ as compared to $\mathrm{M}=0.38, \mathrm{SD}=1.15$ for the first semester.

\section{Table 10}

Means \& Standard Deviations for Behavior Referrals by Semesters for Total Class

\begin{tabular}{ll}
\hline $1^{\text {st }}$ Semester & $2^{\text {nd }}$ Semester \\
\cline { 2 - 2 }$=0.38$ & $\mathrm{M}=0.54$ \\
$\mathrm{SD}=1.15$ & $\mathrm{SD}=1.23$ \\
\hline
\end{tabular}

$\mathrm{n}=78$

Overall, the number of behavioral referrals to the school office for the fourth grade students in 2003-2004 decreased for non "at-risk" students and increased slightly for at- risk students and the total class. 


\section{Parent/Staff Participation Records}

\section{$\underline{\text { Table } 11}$}

Parent Participation by Years for Selected Events

\begin{tabular}{lcc}
\hline Event & 2003 & 2004 \\
Open House - Fall & $\mathrm{f}(\%)$ & $\mathrm{f}(\%)$ \\
Parent Orientation - Fall & $171(60.00)$ & $189(66.00)$ \\
Parent Teacher Conference - Fall & $158(59.00)$ & $157(55.00)$ \\
& $137(48.00)$ & $146(51.00)$ \\
PTO - Winter & & $57(20.00)$ \\
Parent Appreciation Luncheon - Winter & $12(25.00)$ & $134(46.00)$ \\
Parent Teacher Conference - Spring & $123(44.00)$ & $117(41.00)$ \\
Field Day - Spring & $120(42.00)$ & $54(19.00)$ \\
Awards Ceremony - Spring & $63(22.00)$ & $169(59.00)$ \\
\hline $\mathrm{n}=286$ & $192(67.00)$ &
\end{tabular}

Table 11 shows parent participation by years for the 2002-2003 and 2003-2004 school years. In the table, f represents the number of students who were represented with at least one family member at each event. It should be noted that this chart does not include all of the school's events for the two years. Due to the difficulty of maintaining accurate records of parent participation, many instances of parent involvement are not documented. For example, parents dropped by the school to help with a bake sale, assist with the Book Fair, or to share special talents and skills such as presenting golf skills to the physical education classes. These events were not consistently documented.

Staff attendance/participation was mandatory at all events sponsored by the school. Since attendance was mandatory, participation for staff averaged $94 \%$. It also 
should be noted that teacher interviews and parent surveys indicated teachers routinely make themselves available to parents through conferences, phone calls, and "drop-by" visits with parents at the school.

\section{Teacher Perceptions of the School-Home Partnership Model}

The impact of the School-Home Partnership Model was studied in relation to teacher perceptions of the school. Teachers' perceptions were investigated concerning communication with parents, parent/school meetings, and community/school involvement.

A survey (Appendix B) was utilized to collect data concerning teachers' perceptions toward the school. The instrument included both open-ended and closeended items. Table 12 presents the teachers' responses to the eighteen close-ended statements. Due to space limitations, an abbreviated phrase was created for the table representing each of the statements in the survey. The survey statements and their abbreviated phrases follow:

\section{Statements}

1. I provide information about my students' progress so that parents know how their children are performing in school.

2. I provide information about my students' progress so that parents know how their children are performing in school.
Abbreviations

Performance Information

One Teacher Conference 
3. I effectively communicate both positive and negative news about

Positive/Negative News students to their parents.

4. I treat concerns about students with respect and genuine interest in developing solutions.

5. I communicate student expectations to the parents of my students.

Student Expectations

6. The community supports Metter Intermediate School.

Parental Concerns

7. I respond promptly to parent notes and phone calls.

8. Parents should be involved in students' education.

9. The meetings at our school (for example, Open House, Parent Orientation, PTO, MIS School Council) are interesting and helpful.

10. I make parents feel valued and welcomed at our school.

11. I regularly communicate to parents about what is being taught in my classes.

12. I am effective in helping parents know how to help students complete assignments and make good grades.

13. Community involvement is important for a good school.

14. Our school has an active and effective parent organization (PTO).

Parental Welcome

Regular Communication

Effective Communication

Active PTO 
15. People from our community (for example, police officers, nurses,

Community Member Help firemen, etc) come to the school to help students learn important information.

16. I have input into decisions about parent and community involvement at our school.

17. The parents of my students regularly Parent PTO Participation attend PTO meetings.

18. I request information from parents on Request Information their children's talents, interests, or needs.

Teachers were asked to respond "strongly agree", "agree”, "disagree”, or "strongly disagree" to the statements on the survey. Thirteen teachers responded to the survey. Responses are shown by frequency, denoted by "f" on the chart, and parentheses are used to indicate percent of respondents stating "strongly agree", "agree", "disagree", or "strongly disagree". The frequency and percent for items that showed no response are recorded in the "no response" column on the table. Total percentages for each of the statements may add to slightly more or less than $100 \%$ in some instances due to rounding. 
Table 12

Perceptions of the School - Teachers

\begin{tabular}{|c|c|c|c|c|c|}
\hline Statements & $\begin{array}{l}\text { Strongly } \\
\text { Agree } \\
\text { f }(\%)\end{array}$ & $\begin{array}{l}\text { Agree } \\
\text { f }(\%)\end{array}$ & $\begin{array}{l}\text { Disagree } \\
\mathrm{f}(\%)\end{array}$ & $\begin{array}{l}\text { Strongly } \\
\text { Disagree } \\
\mathrm{f}(\%)\end{array}$ & $\begin{array}{l}\text { No } \\
\text { Response } \\
\text { f }(\%)\end{array}$ \\
\hline 1. Pertiomance Information & $8(61.53)$ & $5(38.46)$ & & & \\
\hline 2. ()ne leacher ('onference & $5(38.46)$ & $4(30.76)$ & & $1(7.69)$ & $3(23.07)$ \\
\hline 3. Positive-Negative & $8(61.53)$ & $5(38.46)$ & & & \\
\hline 4. Parental concerns & $13(100.00)$ & & & & \\
\hline 5. Student Fxpectations & $9(69.23)$ & $4(30.76)$ & & & \\
\hline 6. Community Support & 9) $(69.23)$ & $4(30.76)$ & & & \\
\hline 7. Prompt Response & $9(69.23)$ & $4(30.76)$ & & & \\
\hline 8. Parental Involicment & $12(92.30)$ & $1(7.69)$ & & & \\
\hline 9. Meeting Helpfulness & $5(38.46)$ & $8(61.53)$ & & & \\
\hline 10) Parental Weleome 12 & (92.30) & $1(7.69)$ & & & \\
\hline 11. Regular (ommuntcation & $2(15.38)$ & $10(76.92)$ & $1(7.69)$ & & \\
\hline 12. Effective (ommunication & $3(23.07)$ & $9(69.23)$ & $1(7.69)$ & & \\
\hline 13. Community Involvement & $11(84.61)$ & $2(15.38)$ & & & \\
\hline 14. Active PTo & $5(38.46)$ & $7(50.00)$ & $1(7.69)$ & & \\
\hline 15. ('ommunity Member Help & $6(46.15)$ & $5(38.46)$ & $2(15.38)$ & & \\
\hline 16. Teacher Input & $8(61.53)$ & $3(23.07)$ & $2(15.38)$ & & \\
\hline 17. Parent PTO Participation & & $1(7.69)$ & $11(84.61)$ & $1(7.69)$ & \\
\hline 18. Request Information & $1(7.69)$ & $7(50.00)$ & $4(30.76)$ & & $1(7.69)$ \\
\hline
\end{tabular}

The findings indicated that over sixty percent of teachers "strongly agree" (with the remaining percent for each item in the "agree" column) with items $1,3,5,6,7,8,10$, 13 , and 16. These responses show very positive attitudes toward providing information about students' progress to parents, communicating effectively both positive and negative news about student to parents, communicating student expectations to parents, 
experiencing community support for the school, responding promptly to parent notes and phone calls, parental involvement in students' education, making parents feel valued and welcomed at school, involving the community in the school, and having input into decisions about parent and community involvement in the school. Responses to item 4 were $100 \%$ "strongly agree". The responses to this item reflected a very positive attitude towards developing solutions for student concerns with respect and genuine interest.

Teacher responses were also overwhelmingly positive for items $9,11,12,14$, and 15. For these items, 84-100 percent of responses were "strongly agree" and "agree". These items indicated positive teacher attitudes about meetings at the school providing interesting and helpful information, regularly communicating to parents about what is taught in classes, helping parent know how to help students complete assignments and make good grades, an active and effective parent organization, and people from the community coming to the school to help students learn information.

Responses to items 2,17 , and 18 indicated mixed responses. Item 2 requested a response concerning conducting at least one face-to-face conference with all parents of homeroom students this school year. Three teachers gave no response and one indicated "strongly disagree". However, this meant that 69 percent of teachers indicated "strongly agree" or "agree". Responses to item 17 about parents' regular attendance at PTO meetings indicated that 93 percent of teachers indicated "strongly disagree" or "disagree". Lastly, responses to item 18 about teachers requesting information from parents about children's talents, interest, or needs indicated 58 percent either indicated "strongly agree" or "agree". 
In summary, teacher responses were overwhelmingly positive as indicated by the large percentage of "strongly agree" and "agree" responses. Teacher perceptions as indicated by this survey show strong, positive attitudes to communication with parents, parent/school meetings, and community/school involvement.

The survey asked the teachers to complete two short answer responses. The teachers were first asked to name the two most effective things that he/she did to keep parents informed about their child's progress in school. In the teachers' responses student agendas (spirally-bound calendars provided at no-cost to students which provides space for recording assignments and units of study as well as space for parent and teacher notes) were listed by seven of the thirteen teachers. The next most often mentioned method for keeping parents informed about their child's progress in school was phone calls by six of the thirteen teachers. Parent/teacher conferences were included in four of the teacher responses. Other strategies included were: sending graded work home in a timely manner, sending home test results, progress reports, letters, and monthly reports concerning reading program.

The second open-ended response asked for teachers' input about how parent and/or community involvement could be improved at the school. All suggestions provided by teachers involve increasing parent/community/school communication. The suggestions include:

1. have a day or two when parents shadow children.

2. invite all parents (make a real effort) to give their time and input in things that will make our school a better place to educate children. 
3. send positive, individual post cards to students randomly to all students.

4. incorporate family science night and family math night into PTO programs (students, parents, and teachers are involved) and reward students and parents for attending school events such as PTO, family nights, etc.

5. give more incentives for parents to come to school.

6. focus more on careers utilizing parent talents and interest.

7. invite more community helpers to come and share.

8. send letters home in parents' home language.

9. require teachers to send home newsletters to inform parent about what is being taught in the classroom and details about upcoming events (in addition to our school newsletter).

10. provide a suggestion box/brag box for parents and community members.

\section{Student Perceptions of the School-Home Partnership Model}

The impact of the School-Home Partnership Model was studied in relation to both non "at-risk" and "at-risk" student perceptions of the school. Student perceptions were investigated concerning parental and community involvement with their teachers, school, and their schoolwork.

A student survey was utilized to collect data concerning student perceptions of the school. The instrument included both open-ended and close-ended items. Since the researcher wanted to compare the impact of the School-Home Partnership Model on "atrisk" students to non "at-risk" students, placing an identifier for student surveys for "at- 
risk" students ensured confidentiality. This was accomplished by a difference in the placement of one word on the student survey. In order to delineate for the researcher the responses of "at-risk" students and non "at-risk" students, on the surveys for "at-risk" students, the word "about" was located on the second line of the instructions for the survey (Appendix D). The survey for non "at-risk" students (Appendix E) contained the word "about" on the first line of the instructions for the survey.

Table 13 presents the non "at-risk" student responses to the twelve close-ended statements. Due to space limitations, an abbreviated phrase was created for the table representing each of the statements in the survey. The survey statements and their abbreviated phrases follow:

\section{$\underline{\text { Statements }}$}

1. My parent/s usually help me with my homework.

2. I use my agenda to help me get my schoolwork completed.

3. My parent/s feel welcome at school.

4. My parent/s volunteer to do things in my school or classroom.

5. My parent/s come to school meetings and events.

6. My teachers send home my work for my parent/s to see.

7. My teachers send notes home to my parent/s.

\section{$\underline{\text { Abbreviations }}$}

Parental Homework Help

Agenda Helpfulness

Parents Welcome

Parent Volunteers

Parent Attendance

Work Sent Home

Notes Sent Home 
8. My teachers call my parent/s.

9. My teachers send email messages to my parent/s.

10. My teachers send invitations to my parent/s for school programs, class celebrations, and other special events.

11. My parent/s know what I'm studying in school.

12. People from our community (for example nurses, firemen, police officers) come to my school to help me learn important information.
Teacher Phone Calls

Teacher Emails

Teacher Invitations
Parental Knowledge

Community Member Help

Students were asked to respond by indicating, "strongly agree", "agree", "disagree", or "strongly disagree" to the statements on the survey. Eighty-nine non "atrisk" students responded to the survey. Responses are shown by frequency, denoted by "f" on the chart, and percent of respondents stating, "strongly agree", "agree", "disagree", or "strongly disagree". Parentheses are used to indicate percent. Total percentages for each of the statements may add to slightly more or less than $100 \%$ in some instances due to rounding. Chi-square for goodness of fit test was utilized to determine if frequency results fit an evenly distributed pattern expected on the basis of chance or showed a specific pattern indicating positive or negative attitudes. An alpha level of .01 was used to determine statistical significance. Items marked with an asterisk were found to be statistically significant. 
Table 13

Perceptions of the School - Non "At-Risk" Students

\begin{tabular}{|c|c|c|c|c|c|}
\hline Statements & $\begin{array}{l}\text { Strongly } \\
\text { Agree } \\
\text { f }(\%)\end{array}$ & $\begin{array}{l}\text { Agree } \\
f(\%)\end{array}$ & $\begin{array}{l}\text { Disagree } \\
\mathrm{f}(\%)\end{array}$ & $\begin{array}{c}\text { Strongly } \\
\text { Disagree } \\
\mathrm{f}(\%)\end{array}$ & Chi-sq \\
\hline 1. Parental Homew ork Help & $18(20.22)$ & 59) $(66.29)$ & $10(11.23)$ & $2(2.24)$ & $87.69 *$ \\
\hline 2. Agenda Helptulness & $32(35.95)$ & $36(40.44)$ & $10(17.97)$ & $5(5.61)$ & $28.24 *$ \\
\hline 3. Parents Welcome & 49 (55.05) & $37(41.57)$ & $3(3.37)$ & & $59.78^{*}$ \\
\hline 4. P'arent Volunters & $19(21.59)$ & $27(30.68)$ & $33(37.50)$ & $9(10.22)$ & $14.73 *$ \\
\hline 5. Parent Altendance & $24(20.90)$ & $42(47.19)$ & $19(21.34)$ & $4(4.49)$ & $19.59 *$ \\
\hline 6. Work Sent Home & $31(34.83)$ & $38(42.69)$ & $16(17.97)$ & $4(4.49)$ & $17.78^{*}$ \\
\hline 7. Notes Sent Home & $21(23.59)$ & $40(44.94)$ & $17(19.10)$ & $11(12.35)$ & $21.41 *$ \\
\hline 8. Teacher Phone ('alls & $4(+.49)$ & $25(28.08)$ & $27(30.33)$ & $32(35.95)$ & 0.92 \\
\hline 9. Teacher tmails & $5(5.61)$ & $8(8.98)$ & $27(30.33)$ & $49(55.05)$ & $56.33^{*}$ \\
\hline 10. Teacher Invitations & 39) $(43.82)$ & $35(39.32)$ & $15(16.85)$ & & $23.05^{*}$ \\
\hline 11. Parental Knowledge & $45(51.13)$ & $26(29.54)$ & $6(6.81)$ & $1(1.13)$ & $56.47 *$ \\
\hline 12. Community Member Help & $33(37.07)$ & $48(53.93)$ & $5(5.61)$ & $3(3.37)$ & $36.23 *$ \\
\hline
\end{tabular}

$n=89$

The findings indicated that the majority of non "at-risk" students "strongly agree" or "agree" that their parents usually help them with homework, feel welcome in the school, come to school meetings and events, and know what they are studying at school. Additionally, the majority of non "at-risk" students "strongly agree" or "agree" they used agendas to help them get schoolwork completed, teachers sent home their work for their parents to see, their teachers sent home notes to their parents, their teachers sent invitations to their parents for class and school events, and that people from the community came to school to help them learn important information. All of these responses were statistically significant at an alpha level of .01. 
Non "at-risk" student responses to whether or not their parents volunteered to do things in their classrooms and/or school (item number 4) showed that approximately $48 \%$ of the students "strongly disagree" or "disagree" with this item. Also, student responses to whether or not their teachers sent email messages to their parents showed that approximately $85 \%$ of students "strongly disagree" or "disagree" with this item. Both of these survey items were statistically significant at alpha level of .01 . The only item that was not statistically significant at an alpha level of .01 level was item 8 concerning whether teachers called their parents.

Students were asked to response to one open-ended item concerning what would make the school a better school. Seventy-seven non "at-risk" students responded. Approximately $25 \%$ of the comments were related to increasing activities and events for parents and students. Themes that were evident include students being involved in more activities like a school newspaper, boys and girls clubs, events in the community, school assemblies and performance, more field trips and fun activities, and more parent participation. Improving the playground with extra equipment was mentioned in over $10 \%$ of the comments.

In summary, non "at-risk" students as measured by the student survey showed positive perceptions concerning parental and community involvement with their teachers, school, and their schoolwork.

Table 14 presents "at-risk" students responses for each of the twelve closed-ended statements in the survey instrument. The abbreviated phrases used for this table are the same as those for the non "at-risk" students' survey. 
Again, chi-square for goodness of fit test was used to determine whether frequency results fit an evenly distributed pattern expected on the basis of chance or showed a specific trend indicating positive or negative perceptions. An alpha level of .01 was utilized to determine statistical significance. Survey items identified with an asterisk were found to be statistically significant.

\section{Table 14}

Perceptions of the School - "At-Risk" Students

\begin{tabular}{|c|c|c|c|c|c|}
\hline Statements & $\begin{array}{l}\text { Strongly } \\
\text { Agree } \\
\text { f }(\%)\end{array}$ & $\begin{array}{l}\text { Agree } \\
\text { f }(\%)\end{array}$ & $\begin{array}{l}\text { Disagree } \\
\mathrm{f}(\%)\end{array}$ & $\begin{array}{l}\text { Strongly } \\
\text { Disagree } \\
\text { f }(\%)\end{array}$ & Chi-sq \\
\hline 1. Parental Homework Help & $14(23.33)$ & $37(61.66)$ & $8(13.33)$ & $1(1.66)$ & $48.68^{*}$ \\
\hline 2. Agenda Helpfulness & $18(30.50)$ & $29(49.15)$ & $5(8.47)$ & $7(11.86)$ & $24.61 *$ \\
\hline 3. Parents Welcome & $26(43.33)$ & $31(51.66)$ & $3(5.00)$ & & $34.74 *$ \\
\hline 4. Parent Volunteers & $12(20.00)$ & $26(43.33)$ & $13(21.66)$ & $9(15.00)$ & $11.34^{*}$ \\
\hline 5. Parent Atendance & $11(18.33)$ & $32(53.33)$ & $13(21.66)$ & $4(6.66)$ & $28.68^{*}$ \\
\hline 6. Work Sent Home & $25(41.66)$ & $25(41.66)$ & $5(8.33)$ & $5(8.33)$ & $26.68^{*}$ \\
\hline 7. Notes Sent Home & $18(30.00)$ & $26(43.33)$ & $13(21.06)$ & $3(5.00)$ & $18.54^{*}$ \\
\hline 8. Teacher Phone Calls & $10(10.06)$ & $18(30.00)$ & $18(30.00)$ & $14(23.33)$ & 2.94 \\
\hline 9. Teacher Fmails & $1(1.66)$ & $6(10.00)$ & $27(45.00)$ & $20(+3.33)$ & $36.14^{*}$ \\
\hline 10. Teacher Invitations & $23(38.98)$ & $24(40.67)$ & $9(15.25)$ & $3(5.08)$ & $23.54 *$ \\
\hline 11. Parental Knowledge & $26(+4.06)$ & $22(37.28)$ & $10(16.94)$ & $1(1.09)$ & $26.08^{*}$ \\
\hline 12. Community Member Help & $20(34.48)$ & $20(34.48)$ & $9(15.51)$ & $9(15.51)$ & 8.14 \\
\hline
\end{tabular}

$\underset{\substack{d i=3 \\ n=59}}{2}$

The findings indicate that a majority of "at-risk" students "strongly agree" or "agree" that their parents usually helped them with homework, felt welcome in the school, came to school meetings and events, and knew what they are studying at school. Additionally, the majority of non "at-risk" students "strongly agree" or "agree" that they 
used agendas to help them get schoolwork completed, teachers sent home their work for parents to see, teachers sent home notes to their parents, teachers sent invitations to their parents for class and school events, and parents volunteered to do things in their classroom and school. All of these responses were statistically significant at an alpha level of .01 .

Unlike the responses of the non "at-risk" students, "at-risk" students' responses to item 12 about whether people from the community came to school to help them learn important information were not statistically significant. The majority of non "at-risk" students indicated "strongly agree" and "agree" for this item.

Responses for both non "at-risk" students and "at-risk" students for the item about whether teachers called their parents were not significant at an alpha level of .01. the Both risk groups' responses to the item about whether teachers sent email messages to their parents indicated the majority of responses as "strongly disagree" and "disagree". These responses were statistically significant at an alpha level of .01.

"At-risk" students were asked to respond to the same open-ended item concerning what would make the school a better school. A need for more playground equipment was expressed in approximately $20 \%$ of the comments. Approximately $10 \%$ of non "at-risk" students mentioned this same need. Approximately $14 \%$ of "at-risk" students comments related to increased activities such as summer school, more materials for classroom use, more learning time, and more field trips. 


\section{$\underline{\text { Parent Perceptions of the School-Home Partnership Model }}$}

The impact of the School-Home Partnership Model was studied in relation to parent perceptions of the school. The perceptions of parents of non "at-risk" students and "at-risk" students were investigated concerning communication with teachers, parent/school meetings, and community/school involvement.

A parent survey was utilized to collect data concerning parent perceptions of the school. The instrument included both open-ended and close-ended items. Since the researcher wanted to compare the impact of the School-Home Partnership Model on "atrisk" students to non "at-risk" students, placing an identifier for parent surveys for parents of "at-risk" students" ensured confidentiality. This was accomplished by a difference in the placement of one word on the parent survey. In order to delineate for the researcher the responses of parents of "at-risk" students and non "at-risk" students, on the survey (Appendix H) for parents of "at-risk" students, the word "about" was located on the second line of the instructions for the survey. The survey for parents of non "at-risk" students (Appendix I) contained the word "about" on the first line of the instructions for the survey.

Table 15 presents the responses of the parents of non "at-risk" students to the twenty close-ended statements. Due to space limitations, an abbreviated phrase was created for the table representing each of the statements in the survey. The survey statements and their abbreviated phrases follow: 
$\underline{\text { Statements }}$

1. I am provided enough information about my child's progress so that I know how he/she is performing in school.

2. I have had at least one face-to-face conference with my child's homeroom teacher this school year.

3. I am confident that I can easily contact my child's homeroom teacher if a problem arises.

4. My child's teacher sends home student work for me to review on a regular basis.

5. My child's teachers effectively communicate both positive and negative news about my child.

6. My concerns about my child are treated with respect and genuine interest in developing solutions.

7. I know what is expected of me by MIS in order to help my child experience success.

8. Community members come to our school to help students learn important information.

9. I am knowledgeable about programs and activities at MIS.

10. The meetings I have attended at MIS this year (for example: Open House, Parent Orientation, PTO, School Council) have been interesting and helpful.
Abbreviations

Performance Information

One Teacher Conference

Contact Teacher

Regular Work Review

Positive-Negative

Parental Concerns

MIS Expectations

Community Member Help

Program Knowledge

Meeting Helpfulness 
11. My child's teacher knows and appreciates my child's unique abilities and interests.

12. I feel welcome at MIS.

Welcome at MIS

13. My child's agenda provides helpful information about what Child Uniqueness is studied in school.

14. My child's teacher/s regularly communicated with me about what is being taught.

15. I feel that I can help my child complete assignments and make good grades.

16. I have input into decisions that are made at school.

Agenda Helpfulness

Regular Communication

Assist with Homework

Decision Input

17. The community supports MIS.

Community Support

18. I regularly attend Parent Teacher

Meeting Attendance Organization (PTO) meetings and other special events at the school.

19. I volunteer to help in my child's classroom or the school in general.

Parent Volunteers

20. I could better assist my child Teacher Ideas learn if teachers gave me more ideas.

Parents were asked to respond by indicating "strongly agree", "agree", "disagree", or "strongly disagree" to the statements on the survey. Forty-four of the parents of non "at-risk" students responded to the survey. Responses are shown by frequency, denoted by "f" on the chart, and percent of respondents stating "strongly agree", "agree", 
"disagree", or "strongly disagree". Parentheses are used to indicate percent. Total percentages for each of the statements may add to slightly more or less than $100 \%$ in some instances due to rounding. Chi-square for goodness of fit test was utilized to determine if frequency results fit an evenly distributed pattern expected on the basis of chance or showed a specific pattern indicating positive or negative perceptions. An alpha level of .01 was used to determine statistical significance. Items marked with an asterisk were found to be statistically significant. 


\section{$\underline{\text { Table } 15}$}

Perceptions of the School - Parents of Non "At-Risk" Students

\begin{tabular}{|c|c|c|c|c|c|}
\hline Statements & $\begin{array}{l}\text { Strongly } \\
\text { Agree } \\
\mathrm{f}(\%)\end{array}$ & $\begin{array}{l}\text { Agree } \\
\text { f }(\%)\end{array}$ & $\begin{array}{l}\text { Disagree } \\
\mathrm{f}(\%)\end{array}$ & $\begin{array}{l}\text { Strongly } \\
\text { Disagree } \\
\text { f }(\%)\end{array}$ & Chi-sq \\
\hline 1. Performance Information & $15(34.09)$ & $25(56.81)$ & $3(6.81)$ & $1(2.27)$ & $34.18^{*}$ \\
\hline 2. One leacher Conference & $24(54.54)$ & $12(27.27)$ & $6(13.63)$ & $2(4.54)$ & $25.08^{*}$ \\
\hline 3. Contact Teacher & $28(65.11)$ & $13(30.23)$ & $2(4.65)$ & & $46.27^{*}$ \\
\hline 4. Regular Work Review & $16(36.36)$ & $25(56.81)$ & $3(6.81)$ & & $25.90^{*}$ \\
\hline 5. Pusitive-Negative & $17(39.53)$ & $20(46.51)$ & $6(13.95)$ & & $12.90^{*}$ \\
\hline 0. Parental C'uncerns & $17(38.63)$ & $27(61.36)$ & & & $20.54^{*}$ \\
\hline 7. MIS Ixpectations & $19(43.18)$ & $23(52.27)$ & $2(4.54)$ & & $22.27^{*}$ \\
\hline 8. Community Member Help & $11(25.58)$ & $30(69.76)$ & $2(4.65)$ & & $40.18^{*}$ \\
\hline 9. Program Knowiledge & $17(39.53)$ & $22(51.16)$ & $4(9.30)$ & & $18.82^{*}$ \\
\hline 10. Meeting Helpfulness & $16(37.20)$ & $27(62.79)$ & & & $25.54^{*}$ \\
\hline 11. Child Uniqueness & $17(38.63)$ & $22(50.00)$ & $5(11.36)$ & & $17.54^{*}$ \\
\hline 12. Welcone at MIS & $28(63.63)$ & $16(36.36)$ & & & $28.54^{*}$ \\
\hline 13. Agenda Helpfulness & $19(43.18)$ & $18(40.90)$ & $7(15.90)$ & & $11.72 *$ \\
\hline 14. Regular Communication & $5(11.36)$ & $22(50.00)$ & $16(30.36)$ & $1(2.27)$ & $25.63^{*}$ \\
\hline 15. Assist with Homework & $17(38.63)$ & $26(59.09)$ & $1(2.27)$ & & $32.81^{*}$ \\
\hline 16. Decision Input & $7(16.27)$ & $23(53.48)$ & $13(30.23)$ & & $14.90^{*}$ \\
\hline 17. Community Support & $16(37.20)$ & $25(58.13)$ & $2(4.65)$ & & $27.45^{*}$ \\
\hline 18. Meeting Attendance & $9(21.42)$ & $24(57.14)$ & $9(21.42)$ & & $16.08^{*}$ \\
\hline 19. Parent Volunteers & $12(27.90)$ & $20(46.51)$ & $11(25.58)$ & & 7.45 \\
\hline 20. Teacher Ideas & $3(6.97)$ & $27(62.79)$ & $12(27.90)$ & $1(2.32)$ & $38.26^{*}$ \\
\hline
\end{tabular}

The findings indicated that all responses of parents of non "at-risk" students were statistically significant at the .01 alpha level except item 19 concerning whether parents volunteered to help in their child's classroom or the school. The majority of the 
responses for each of these statistically significant items indicate "strongly agree" or "agree". These positive response items include: receiving enough information about children's progress in school, at least one face-to-face conference with their children's teachers, confidence that their child's homeroom teacher can be easily contacted, receiving student work to review on a regular basis, receiving positive and negative news about their children, an attitude of respect and genuine interest in concerns, understanding school expectations, knowledgeable about programs and activities at the school, helpful meetings such as at PTO, felling welcome at the school, usefulness of children's agendas, input into decisions at the school, acknowledging community support for the school, and the perception that their children could learn more if teachers gave more ideas.

Parents of non-at risk students were asked to response to two open-ended items. The thirty-two responses to the first item concerning the most helpful things that my child's teacher(s) do to help my child in school generated several themes. Twenty-five percent of the responses indicated that the student agendas were very helpful. Approximately $50 \%$ of responses identified warmth, caring, and personal attention. Examples of comments included:

1. creating trust and independence.

2. creating a positive environment and encouraging each child to fulfill their potential.

3. providing positive reinforcement for good behavior.

4. being attentive and understanding.

5. communicating positive and negative aspect of my child's performance and behaviors. 
6. caring and respectful attitude toward my child.

7. displaying positive attitudes (teachers).

8. respecting individuality.

9. encouraging child to be his best.

Thirty-one parents of non "at-risk" students responded to the second open-ended item about how the school could better serve them and their child. Thirty-three percent of these responses related to suggestions for increasing communication between the home and school. Examples of suggestions included:

1. increase the number of parent/teacher conferences.

2. check consistently to see that students have written down assignments in agendas before they leave school.

3. update grades in the computerized grade system more often (parents have access to grades through internet.

4. increase parental awareness of topics of study.

5. utilize agendas more thoroughly for information about curriculum.

6. give more advance notice of meetings and events.

7. provide mid-term progress report at all grade levels.

Table 16 presents responses of parents of "at-risk" students for each of the twenty-one closed-ended statements in the survey instrument. The abbreviated phrases used for this table are the same as for the survey for parents of non "at-risk" students. 
Due to the small number of respondents to this survey, chi-square for goodness of fit was not used. Responses are shown by frequency, denoted by "f" on the chart, and percent of respondents selecting "strongly agree", "agree”, "disagree", or "strongly disagree". Parentheses are used to indicate percent. Total percentages for each of the statements may add to slightly more or less than 100 percent in some cases due to rounding. A "no response" category indicates survey items that received no response. 


\section{Table 16}

Perceptions of the School - Parents of "At-Risk" Students

\begin{tabular}{|c|c|c|c|c|c|}
\hline Statements & $\begin{array}{l}\text { Strongly } \\
\text { Agree } \\
\text { f }(\%)\end{array}$ & $\begin{array}{l}\text { Agree } \\
\mathrm{f}(\%) \\
\end{array}$ & $\begin{array}{l}\text { Disagree } \\
\mathrm{f}(\%)\end{array}$ & $\begin{array}{l}\text { Strongly } \\
\text { Disagree } \\
\mathrm{f}(\%)\end{array}$ & $\begin{array}{l}\text { No } \\
\text { Response } \\
\quad \mathrm{f}(\%)\end{array}$ \\
\hline 1. Performance Information & $5(31.25)$ & $9(56.25)$ & $2(12.50)$ & & \\
\hline 2. contact teacher & $7(43.75)$ & $9(56.25)$ & & & \\
\hline 3. Homeroom contact & $7(43.75)$ & $9(56.25)$ & & & \\
\hline 4. Regular Work Review & $6(37.50)$ & $7(43.75)$ & $3(18.75)$ & & \\
\hline 5. Positive-Negative & $4(25.00)$ & $12(75.00)$ & & & \\
\hline 6. Parental Concerns & $6(37.50)$ & $9(56.25)$ & & & $1(0.25)$ \\
\hline 7. MIS Expectations & $6(37.50)$ & $9(56.25)$ & & & $1(6.25)$ \\
\hline 8. Conmunity Member Help & $5(31.25)$ & $9(56.25)$ & $1(6.25)$ & & $I(0.25)$ \\
\hline 9. Program Knowledge & $3(18.75)$ & $11(68.75)$ & $2(12.50)$ & & \\
\hline 10. Mceting Helpfulness & $5(31.25)$ & $11(68.75)$ & & & \\
\hline 11. (hild Uniqueness & $3(18.75)$ & $12(75.00)$ & & & $1(0.25)$ \\
\hline 12. Welcome at MIS & $8(50.00)$ & $8(50.00)$ & & & \\
\hline 13. Agenda Ilelpfulness & $7(43.75)$ & $7(43.75)$ & $1(0.25)$ & $1(6.25)$ & \\
\hline 14. Regular Communication & $5(31.25)$ & $10(62.50)$ & & $1(0.25)$ & \\
\hline 15. Assist with homework & $7(43.75)$ & $7(43.75)$ & $2(12.50)$ & & \\
\hline 16. Decision Input & $1(6.25)$ & $11(68.75)$ & $1(6.25)$ & $2(12.50)$ & $1(0.25)$ \\
\hline 17. Community Support & $4(25.00)$ & $10(62.50)$ & $1(6.25)$ & & $1(6.25)$ \\
\hline 18. Meeting Attendance & $1(6.25)$ & $8(50.00)$ & $5(31.25)$ & $1(6.25)$ & $1(6.25)$ \\
\hline 19. Parent Volunteers & $4(25.00)$ & $6(37.50)$ & $6(37.50)$ & & \\
\hline 20. Teacher Ideas & $+(25.00)$ & $9(56.25)$ & $2(12.50)$ & & $1(0.25)$ \\
\hline
\end{tabular}

The majority of responses to each item were "strongly agree" and "agree" for all items. These items related to receiving enough information about children's progress in school, at least one face-to-face conference with their children's teachers, confidence that 
their child's homeroom teacher can be easily contacted, receiving student work to review on a regular basis, receiving positive and negative news about their children, an attitude of respect and genuine interest in concerns, understanding school expectations, knowledgeable about programs and activities at the school, helpful meetings such as at PTO, feeling welcome at the school, usefulness of children's agendas, input into decisions at the school, acknowledging community support for the school, and the attitude that children could learn more if teachers gave parents more ideas. Two items that contained more than $35 \%$ of responses of "strongly disagree" and "disagree" concerned whether parents volunteered in their children's classroom and in the school and if they regularly attended PTO meetings.

Parents of "at-risk" students were asked to respond to two open-ended items. The eleven responses to the first item concerning the most helpful things that my child's teacher(s) do to help my child in school included the following ideas: making modifications for special needs, working closely with individuals, and listening. The ten responses to the second item concerning how could the school better serve the parent and child produced the following ideas: check agendas to make certain homework is written down before children leave school each day, provide fun activities for the children, and recognize the good work done by the teachers. 


\section{Key Informant Interviews}

Teachers at the school were used as key informants regarding the School-Home Model. Semi-structured interviews with the principal investigator were conducted in order to gain understanding of the model and to obtain suggestions for increasing the staff's effectiveness in reaching out to families. In order to provide confidentiality, any direct quotes from individual teachers were identified as T1, T2, etc.

The list of interview questions is as follows:

1. How are parents involved at our school?

2. What are the best ways to keep parents informed about their child's progress in school?

3. In what ways do you communicate with parents? Which ways are the most effective?

4. What strategies do you use to get to know your students and their parents?

5. Do you ever invite parents to come to school? If yes, tell some of the reasons you have invited them. What were the results?

6. What is the role of the teacher in home-school communication?

7. How could our school increase parent participation in children's education? What differences, if any, are there between involving parents of "at-risk" students (special education or Early Intervention Program students) and non "at-risk" students?

8. Do you give any specific help to parents in order for them to assist their child with academics? If so, please explain.

9. What are the advantages/disadvantages of our school agendas? How can we use them more effectively?

10. Is there anything else you would like to say about our school? What can we do to improve home-school communication, student behavior, and academic success? 
Responses to the interview question concerning how parents were involved at the school provided evidence of formal and informal opportunities for parents to be involved. Examples of traditional participation included meetings of the Parent Teacher Organization (PTO), parent-teacher conferences, phone calls to and from staff members, volunteering to provide assistance with field trips, participation in Open House at the beginning of the school year and Parent Orientation meetings, Book Fairs, contributing to bake sales, donating money and/or items for needy children, donating items needed by the school such as sand, dirt, and pine straw, attendance and assistance with Science Fairs, and reading and acknowledging receipt of monthly school newsletters.

Examples of participation opportunities that could be viewed as less traditional include: involvement of parents in use of student agendas (spirally-bound calendars provided at no-cost to students that provides space for recording assignments and units of study as well as space for parent and teacher notes), attendance of parents at Jeopardy quizzes (involves students in competition utilizing questions based on the school's curriculum in an electronic, simulated game format), Parent Appreciation Luncheon that included educational door prizes for parents and students, involvement of parents in teaching of units of instruction such as golf in physical education classes, and participation in school council meetings [In Georgia, these councils are mandated by law to include at a minimum the school principal, two teachers at the school, two parents of children at the school, and two businesspersons and are viewed as advisory groups to the schools and boards of education (Georgia School Council Institute, 2000).]

An insight provided by $\mathrm{T} 4$ indicated, 
"I can't remember everything that's gone on, but I just see that it seems like more parents are concerned ... stopping by the school or calling the school or sending notes wanting to know what's going on ... and they send money, stuff for the bake sale. . collecting for the cancer society and extra money for going on a field trip for a child that may not have a way to go."

Additionally, T1 commented, "Parents are involved because teachers see so many of them each nine weeks or they call them on the phone and they come for conferences." These comments indicate an atmosphere of parent responses to and from the school and presence in the school.

In response to questions two and three concerning the best ways to keep parents informed about their child's progress in school, fifty percent of the teachers identified phone calls. T4 summarized the importance of phone communication as,

"I'm a believer in getting on the telephone. I do think it's good to have a phone in your room and it's nothing like talking -personal talking about what I'm seeing in the child. You don't have to wait around to call. They're right there. And, sometimes, you let the child go with you to the phone to talk to so-and-so and he's going to explain to you what's going on."

Student agendas (spirally-bound calendars provided at no-cost to students which provides space for recording assignments and units of study as well as space for parent and teacher notes) were identified by ninety percent of the teachers as an effective way to keep parents informed about their child's progress. T7 described the value of agendas, as ". . . the agendas that the children have are great communication pieces if you use them correctly. And I just think that is the best way because all of the time, you just can't get to the telephone to call parents but using those agendas have been the best way in communicating with them. I have parents that write notes back to me and I write parents notes to them and also, when a child is going to be out, they let me know by writing it in the agenda that the child will be out." 
Other responses from teachers indicated agendas as part of the formula of total communication with parents. As T5 indicated, "The best way I think is face to face communication. That isn't always possible or feasible but I think it's the most effective. There's always a phone call. I know you can't do that all of the time but it certainly works well. The agenda works well for daily communication."

Since approximately ten percent of the school population is Hispanic, there was evidence that teachers have found some ways to overcome language barriers. For example, T8 indicated, “. . . a list of phrases in Spanish to the teachers so that they could write down in the agenda in Spanish ... I know, for sure, that some are ... that's a helpful way."

Perhaps, T9 summarized the gist of teacher responses with her comment that the best way to keep parents informed about their child's progress in school is frequent communication. It is apparent by the teachers' answers that multiple, on-going communication was taking place in the school. In addition to agendas, phone calls, and face to face communication, teachers send home graded papers, conduct informational meetings such as Open House, send home mid-term reports of student progress, school newsletters, and have a method for keeping parent information such as phone numbers and email addresses handy so that communication can readily happen.

A number of teacher's comments reflect the importance of personal communication. As T8 explained,

". . . the most effective way, really, is person to person, talking to them whey they come or telephone calls. Because I know that way, for me, and seeing them when they come to my room, I can explain to them in a little 
more detail what is going one. For me, I can't write everything in the agenda that they would need to know."

Teachers' access to phones was noted as very important in the success of phone communication. As noted by T9, "It helps having the phone in the room-it does. Not that you would stop teaching and call but during my planning period, we call a lot of parents then and before school and after."

It was obvious that teachers' efforts to communicate with parents were facilitated by administrative decisions such as having phones in classrooms, release time for parentteacher conferences, planning periods, school-wide newsletters, and purchased materials such as student agendas. However, individual teacher commitment was necessary as T7 indicated, "I think it's (communication's) just something individual teachers choose to do."

Question four related to strategies used to get to know the students and their parents. Themes in teachers' responses included: meeting with parents, providing an open door policy to the classroom, sending home introductory letters, conducting required conferences, providing questionnaires to child and parent about interests, providing students with opportunities to write about themselves, completing interest inventories, talking informally with students and parents at ball park, etc., communicating with former teachers of the students, greeting students when arriving at school, learning the culture of the home, knowing where the children and their families live, giving a ride to church or community events, organizing special board displays in room about 
individual children and their families, and being generally approachable and available to students and their families.

T6 obviously understands that establishing rapport with some students and families involves communication away from the school campus. She said, "I also go out in the community, watching football games and talking. I get out of the building." A similar view was expressed by T2, "One on one interaction with kids, just talking with them and sometimes, joking with them. They react to that."

The best way to get to know your students and parents is to approach formal opportunities such as teacher-parent conferences as a means to establish rapport. For example, as T7 indicated, "When I have conferences, I'll invite the parent to come in and to talk about their child. But before I start my conferences, I always ask the parent how they are doing and they give me a little information bout themselves through just asking that question."

T4's comments provides insight into the conscious effort required to lay the groundwork for knowledge of students and their lives when she said, " . . the main thing - through the year you learn that child by talking to that child and allowing that child to come up to you, especially during a recess time or down time to talk to you about things that are going on in their lives or whatever. When you see a strategy, I think you have to allow yourself to be open or seek a rapport with a child enough that they feel comfortable coming to you and approaching you and saying that soand-so is going on. That's the strategy - developing a rapport with a child that they feel like they can talk to you .... your demeanor-how you react to children. . . you can either be of course I want to hear this or don't bother me." 
Question five regarding whether the teacher invited parents to come to school and the reasons and responses, produced mixed results. T10 stated, "I guess I probably should more than I do. It doesn't occur to me a lot of times to invite them." Additionally, T4 stated,

"No, I do not. I think it's a good thing but the problem (or excuse) is that I don't have the time. I think it lends itself to what type of subject you're teaching as far as a parent coming to help out and share something in a certain curriculum or whatever. They're welcome to come, I don't know that I've ever issued it."

It is important to consider that even though T7 indicated a lack of direct success

from invitations, the teacher was successful in providing an atmosphere that welcomed parents. As she said,

"I haven't been very successful in that, when you invite them, they've got their own agenda. One particular parent ... she (the child) really didn't need the parent there, but I felt that the parent thought she needed to be there sometimes and so, in the morning times, she would come in with the child. I know it may have bothered some people, but it didn't bother me because, I don't know, I thought she felt she needed it or the child may have in some way that I couldn't see. Yeah, and they get a good feeling about things like that when they are able to come into the classroom and they're not feeling that you don't want them there. Yes, and I want to try and give that feeling to all of my parents so that I don't mind them coming in to my classroom because, of course, I'm not going to be doing anything I'm not supposed to."

As in the teacher's response above, a number of responses indicated an attitude of openness, acceptance, continual flow of invitations, and building on successes through positive experiences at school events. For example, T5 stated, 
"I've certainly invited them to PTO. Not all come to that. I've invited them to come and participate when we've had field day activities. Some to cook for activities. I've invited them to come for Honors Day programs and invited for the parent lunches. I try to tell my parents that if they need to come by for anything to stop by ant time they need to and when I get to a good stopping point, I'll be glad to talk to them."

T6's comments further support this idea,

"I've invited parents, usually for fun things. Jeopardy football, of course and I usually have children's academic events such as Science Fairs, any of that sort of thing. I've seen parents be there and proud of those students and once to one event, they are eager to come to another. I've often seen a student draw in more parents. They'll talk and say that they really should come."

Further supporting positive, ongoing invitations and openness, T3 said,

“... and ask them to come visit for book fairs and things like that... And they know they are always welcome, I guess that's why I don't make it a deliberate invitation. I send out a letter at the beginning of the year that gives them my phone number at home and also my phone number here and tell them there's an open door policy."

T8 summarized the need for ongoing invitations by stating, "It helps them (parents) to know what's going on here and how the child is doing. It helps them feel more a part of the community as a whole."

Overwhelmingly, the teachers interviewed responded to question six regarding the role of the teacher in home-school communication as the teacher's responsibility. As T4 stated,

"I think it goes back to the teacher setting the tone that they are willing to listen. I think that orientation (meetings) and open house will set the tone 
or you can set the tone during that time... And I think that's its important for all levels of education but some parents feel intimidated by the school situation and I think you certainly need to work on that to make sure they feel welcome and that you understand of whatever."

T5 emphasized that the teacher must be the instigator when she said,

". . if the teacher does not start the process, then there will not be any communication with many of the parents.... I I think it's very important that the teacher makes sure that communication is happening."

The importance of honesty was emphasized by comments similar to T3, "Role of the teacher in home-school communication, I would say, would be to tell the parents up front what is going on with their child. Not telling them what they want to hear but being honest." And, as T11 stated, "My role would be to keep the parent informed on what is going on, whether it be good or bad." T9 stated this involves more that just academic information and should include behavioral and social issues.

A strong commitment to involving parents was needed as noted by T10 regarding scheduled meetings with parents. She says,

"When we set up IEP (Individual Educational Placement meetings for special education students) meetings, the parent will say then can't come but go ahead and have the meeting. Sometimes they don't realize that we can change the time, we can reschedule because I have done that a lot of times. If I have an IEP meeting scheduled, I'll ask the student if his mama is coming. And then, just having them on the phone to talk and realizing that they checked no because they couldn't come at that time but we can reschedule."

In summary, for responses to question 6 , teachers indicated that the teacher must show the initiative in home-school communication, accept that the responsibility for home-school communication and must be the leader in the process. 
Question 7 was a two-part question involving how to increase parent involvement and the differences, if any, between involving parents of "at-risk" students (special education or Early Intervention Program students) and non "at-risk" students. Two suggestions were given for increasing parental involvement to both groups of students and parents. T1 suggested the use of teacher newsletters to parents in addition to the school-wide newsletter. T6 felt that compiling a list of hobbies and special interests from parents might be helpful in identifying parents who would be willing to share information as resource speakers at the school.

Differences in reaching out to parents of "at-risk" students revealed numerous suggestions and insights. As T2 stated, "I really believe that some parents are afraid of the school system, that we a jumping at them and perhaps they don't really trust in the system. Try to reach them at home, if possible. .." T5 elaborated that

"we need more contact with them ("at-risk")-sharing and seeing what you see in the classroom on a regular basis and communicating with them and helping them to understand test results and showing them what progress their child is making or what areas they are struggling in and offer any suggestions that you may think would help with that particular situation."

T4 said,

"I want those parents (parents of "at-risk" students) to come in and sit down during that class time and just watch what's going on and look-this is what we do and what it's all about and to see the relationship or how the teacher is relating the student and what she does in that classroom."

At times alternate activities and focusing on the successes of "at-risk" students were needed. As T3 stated, 
"I think the boys program (for "at-risk" youth through federal and state funds) has involved our children the most in getting parents here because we did the family night and I think they feel that communication, that connection with the community... I think, possibly, because there's been so much negative in an "at-risk" child's life. I think opening up the communication involving positive celebration with children . I find that some of the children I need to see, if I called their parent on the phone, and which we did, you know, I'd call them and say that I wanted to let them know that their child made a 100 on a spelling test. Then that kind of broke a barrier and they were a little less reluctant to come in... I think a lot of personal attention added to the score helps."

In summary, for involvement with parents of "at-risk" students, responses indicated necessity of alternate activities, which may lead to more involvement, commitment to establishing lines of communication based on positive messages, more personal attention, necessity of focusing on overcoming negativism and making experiences with the school non-threatening, and purposefully providing opportunities to celebrate successes of "at-risk" students.

In response to question 8 about specific help given to parents in order to assist their child with academics, the following items were included: providing a course syllabus at the beginning of the year, study guides and flashcards, requiring students to write assignments and topics of study in agendas, calling parents to discuss specific academic concerns, suggestions of books, software, and websites, providing tapes of social studies textbook, checking out personal books to students and parents, connecting parents and students with summer school programs and encouraging summer reading, sending extra practice sheets home with the child, involving parents in helping student 
with organization of notebooks for subject areas. Perhaps T9 described the dedication and tone needed when she said,

"We have conferences. If they call me, yes ... just like (parent's name), I talked with her about how to work with (student's name) because (student) was saying that he didn't need his mother's help, I can study. He'd go back and study for 10,15 , or 30 minutes by himself and then come . . and you can't do that. You've got to call them out to him and that study guide is one way to do it."

In other words, the teacher must help the parent know how to study with the child. A teacher must be tuned in to the specific needs of the parent and child. This view reflects the belief that a parent-teacher conference is not just about reporting how the child is doing but involves specific, individual attention based on the student's and parent's needs.

The advantages and disadvantages of student agendas (spirally-bound calendars provided at no-cost to students which provide space for recording assignments and units of study as well as space for parent and teacher notes) were addressed in question 9. It should be noted that the school has utilized agendas for three years. Students are required to write daily assignments in their agendas. Parents are encouraged to include notes to the teacher in the agendas. Teachers also write notes to parents in the agendas.

Overall responses were very favorable concerning use of student agendas. Advantages included: open communication that is not intimidating to parents, provides awareness to parents of topics being studied, helps students remember needed items such as field trip money, etc., teaches organizational skills, helps parents to know expectations, helps with student behavior because child realizes that notes in agendas are serious and 
must be signed, and mutually supporting the effort of agendas by having school-wide expectations for their use.

Some disadvantages and suggestions emerged. It takes a lot of time to check agendas but numerous teachers have overcome this barrier by assigning student helpers to assist with checking agendas. Lack of parental support in limited cases was a problem, but as T4 indicated..."lots of time (you must) make exceptions. Nothing is one hundred percent all the time." Success of agenda utilization is dependent on knowledge of the child and family. As T1 indicated, “... a lot of times the kids get really upset because their parent comes home really late, so they don't get it done or they are still in bed when the child leaves in the morning."

T9 summarized the overall feeling of the use of agendas by saying, "They're (agendas) wonderful. This is just something I need to do, in making sure that each child writes something in every class. It's hard. But when I do, it makes a difference."

Responses to question 10 concerning what else can be done to improve homeschool communication, student behavior, and academic success provided the following:

1. provide diversity training for staff so as to improve understanding of different cultural backgrounds.

2. make certain that discipline is done privately (not in the hallways).

3. increase information to teachers about standards and expectations for curriculum and behavior.

4. increase personal communication between teacher/grade level and parents.

5. involve all parents no matter what it takes. 


\section{CHAPTER V \\ SUMMARY, IMPLICATIONS, AND RECOMMENDATIONS}

This study investigated the impact of the School-Home Partnership Model at Metter Intermediate School, a small rural school in southeast Georgia. The subjects of this study were parents, students, and teachers of the school. Quantitative methods and interviews were used to collect and analyze data. These methods consisted of document analysis, surveys, and interviews with key informants.

This study was important because the development of practical, effective models of parental involvement holds promise for improving teaching and learning. The School-Home Partnership Model, created for the school by the school's administrators, was based primarily on Reaching Out to Families (Blendinger \& Jones, 2003) and Epstein's (1995) descriptions of overlapping spheres of influence. The assumptions of the model were: (1) mutual respect and trust among the home, school, and community enables the collaboration which leads to school and student improvement; (2) combined resources of the home, school, and community complement each other and increase the opportunities for school and student success; and (3) school staff have primary responsibility for setting the tone for positive, on-going connections with the home and community. 
The study investigated the impact of the School-Home Partnership Model on the students, parents, and teachers in relation to student scores on the Georgia CriterionReferenced Tests (Georgia Department of Education, 1999), student grades on report cards, student daily attendance at school, student behavior referrals to the school office, parent and staff participation in school events and meetings, and student, parent, and teacher perceptions of the school. Chapter V presents the (a) summary of the findings, (b) implications, and (c) recommendations.

\section{$\underline{\text { Summary of the Findings }}$}

The Georgia Criterion-Referenced Competency Tests (CRCT) were used to measure student achievement in relation to the required Georgia Curriculum (Georgia Department of Education, 1999). The reading and math scores for students who experienced the School-Home Partnership Model for two years (fifth graders in 20032004) were examined for changes in achievement. Overall results were mixed.

Increases in reading and math achievement were present. An increase in reading achievement was found for the total class (both risk groups) during the first year the students experienced the School-Home Partnership Model. Math achievement for the total class increased during the second year. There was also an increase in reading achievement for the non "at-risk" students during the first year.

Decreases in achievement in reading and math were evident. For non "at-risk" students, reading achievement decreased during the second year. When the class was considered as a whole (both risk groups), math achievement decreased during the first 
year. The "at-risk" group and the non "at-risk" group also decreased in math achievement during the first year.

Students' achievement in four key academic areas was analyzed using report card grades for a class of students for two years. End of year grades (2002-2003 and 20032004) in reading, English, spelling, and math indicated some changes in achievement. Changes in the means of yearly grades for the class as a whole, the non "at-risk" group, and the "at-risk" group primarily revealed changes of less than two points. Two instances were found in which the means changed by more than two points. For the "atrisk" students, the spelling mean increased from 84.13 to 86.40 (an increase of 2.27 points) and in math from 80.17 to 84.03 (a gain of 3.86 points). Students' achievement in the four key academic areas was also analyzed using report card grades for a second class of students for one year. Semester grades (2003-2004) in reading, English, spelling, and math were virtually unchanged except for a change in means in reading for the "at-risk" students from 84.26 to 87.55 , an increase of 3.30 points from the first semester to the second semester. Overall, report card grades remained virtually the same for the total classes and the two non-risk groups except for the three instances cited above regarding improvement in grades of "at-risk" students.

For two years of attendance records, attendance improved as noted by a decrease in the number of days absent from school. The number of days absent for the total class (both risk groups) decreased from 4.80 to 4.55 , a decrease of 0.25 days. The non "atrisk" group decreased from 4.52 to 4.29 , a decrease of 0.23 . The "at-risk" students improved the most by a change from 5.62 to 5.32 , a decrease of 0.30 days. 
For two years of discipline referrals to the school office, referrals to the school office for "at-risk" students increased from 0.27 to 1.26 , an increase of 0.99 referrals. Referrals for the non "at-risk" students and the total class changed negligibly. For the second class of students whose discipline referrals were analyzed for one year by semesters, only minor changes were evident.

Due to the difficulty of maintaining accurate records of teacher and parent participation in school events, no complete records were available. However, there was evidence of many ongoing and varied events at the school. Parents, students, teachers, and community members attended these events. Examples included: activities during the day and evening for the school Book Fair, Open House at the beginning of each school year, Parent Orientation scheduled during the first few weeks of school, Parent Appreciation Luncheons, Parent Teacher Organization (PTO) meetings which often included student performances, evening programs and meals with parents of primarily "at-risk" students through activities of the after school program, Jeopardy games based on school curriculum, school council meetings, and staff/parent/student volleyball and basketball games.

Non "at-risk" students and "at-risk" students showed clear evidence of similar perceptions toward school. Survey results indicated that the majority of both groups of students believed their parents usually helped them with homework, felt welcome in the school, came to school meetings and events, and knew what they were studying at school. They believed that student agendas were helpful in getting their schoolwork 
completed, teachers sent home their work for their parents to see, teachers sent home notes to their parents, their parents volunteered at the school, and teachers sent invitations for events to their parents. The responses from each group concerning whether teachers called their parents were inconclusive. Both groups indicated that teachers did not send email messages to their parents.

Positive perceptions toward the school were evident by the parents of non "atrisk" students. These parents felt they received adequate information about their child's progress in school, had confidence that they could easily reach the teachers, received positive and negative news about their children, understood school expectations, and felt there was an attitude of respect and genuine interest about concerns. They also reported they felt welcome in school, had input into decisions at the school, and acknowledged that the community supports the school, and their children could learn more if teachers gave them more ideas. In responses to open-ended items on surveys from the parents of non "at-risk" students, school agendas were often mentioned as very helpful as a communication tool. Also, the feelings of personal regard shown by teachers for them and their children were acknowledged.

Parents of "at-risk" students also expressed many positive perceptions toward the school that were very similar to parents of non "at-risk" students. Responses did, however, indicate that more than thirty-five percent of parents did not regularly attend PTO meetings or volunteer in the school. In written comments from the parents of "atrisk" students, appreciation was expressed for individual attention and allowances for individual needs of students. 
Through interviews and surveys, teachers expressed commitment to students and their families. Examples include: regularly providing information to parents about children's progress in school, relaying both positive and negative information to parents, communicating expectations to parents, responding promptly to parent notes and phone calls, and making parents feel valued and welcomed at school. Teachers felt the community supported the school and that this support was needed in order to have a good school. It was evident that teachers believed they regularly communicated to parents about topics of study in their classes. They felt effective in helping parents know how to help students complete assignments and make good grades. According to the teachers, school meetings were interesting and helpful, the school had an active and effective Parent Teacher Organization (PTO), and parents regularly attended PTO. Teachers also felt that people from the community came to help students learn important information. The number of parent/teacher conferences is a concern. Only sixty-nine percent of teachers indicated that they had conducted at least one conference with all of their homeroom students.

Parents, students, and teachers expressed strong, favorable perceptions of the school. Student attendance in school improved, while the number of discipline referrals to the school office increased for "at-risk" students. Quantitative data based on CriterionReferenced Competency Tests (CRCT) showed limited changes. Report card grades showed improvement in grades for "at-risk" students in reading, math, and spelling. 


\section{$\underline{\text { Implications }}$}

Findings from the investigation of the School-Home Partnership Model at Metter Intermediate School suggested seven implications:

1. Parents of both non "at-risk" and "at-risk" students overwhelming believed that they could better assist their children learn if teachers provided more ideas. This should be a priority of the school. Epstein (1995) supported this idea by emphasizing the importance of providing assistance to parents in order to help children in school.

2. Establishing home-school connections are difficult but the study's findings indicated that this connection was strong at the school. Teachers, non "atrisk" students, "at-risk" students, parents of non "at-risk" students, and parents of "at-risk" students overwhelmingly indicated positive perceptions toward the school. These positive perceptions can provide the basis for greater family involvement and success for children as Swap (1993) proposed.

3. While achievement levels of the students as a whole did not drop remarkably, achievement levels did not consistently improve. Identifying students' strengths and weaknesses and selecting appropriate curriculum materials should be a priority.

4. The school has made a concerted, school wide effort to make communication ongoing with parents. Communication was accomplished through student agendas, phone calls, notes and letters, school newsletters, parent/teacher conferences, and school meetings. On a much more limited basis, email and a web-based report card program were utilized. Blendinger \& Jones (2003) believed that every contact with the home provided an opportunity to establish and maintain positive communication with the home. It appeared from the results of this study that communication was positive and on-going.

5. A warm, inviting, family-like atmosphere has been established that offers many opportunities for parents, students, and community members to participate in school events. Swap (1993) emphasized the important of this involvement at the school as important for the success of children.

6. Although the perceptions of the school for parents of "at-risk" students and their parents were positive, the number of behavior referrals to the school office increased for "at-risk" students. 
7. Parents of "at-risk" students report a higher rate of parent conferences that parents of non "at-risk" parent. The school should ensure that conferences take place with all parents.

\section{$\underline{\text { Recommendations }}$}

The perceptions of teachers, students, and parents at the school were positive and reflected an atmosphere of mutual respect and trust between the home and school. It was also obvious that the community supported the school. If these positive relationships are built upon, they may have impact on children's achievement and behavior.

The following recommendations are based on the findings and implications from the study.

1. Teachers need to support parents in children's learning by providing specific guidance to parents about what they can do to help their children at home. In order for some parents to be able to help their children with learning at home, some of them will need to acquire skills and knowledge themselves. Some will just need specific directions about what activities they need to do at home with their children. Teachers should work with key parent leaders through the PTO or school council to develop a plan for providing targeted help to parents that will enable them to help their children succeed at higher levels. The school's monthly newsletter could be expanded to include more suggestions to parents on how to help their children at home. By providing more specific help to parents, higher student achievement can be realized. 
2. On-going efforts should be made to maintain and extend the positive atmosphere of the school. This involves staying in close contact with all constituents through such activities as formal meetings at the school, informal interactions among teachers, students, parents, and community members, conferencing with parents, and collecting information through surveys. In order to provide an on-going positive tone at the school, experienced teachers at the school will need to provide guidance to new teachers. Interactions among parents and personnel at the school should continue to be based on positive relationships, collaboration, and reciprocity. The goal should be for the school's strategies and practices to meet the needs of all parents and all children. In order for this to be a reality, teachers need strong leadership from school administrators and a commitment of resources to family involvement.

3. Ongoing assessments - both formative and summative - should be utilized to guide instruction. Appropriate curriculum materials should be used based on the needs of the children.

4. On-going communication with parents should be a priority. Student agendas should continue to be used as a communication tool between the home and school. The use of agendas can be expanded and used as a means for including more ideas to parents about how they can give specific help to their children. Brief comments and feedback about the progress of home activities can be included. Possibly, agendas with "pockets" can be purchased so that flash cards can be sent between home and school. Attention should be given to developing the use of technology by parents. For example, 
informational sessions should be provided for parents on how to use email programs and use the web-based grade program. This would increase communication between the home and the school and make children's grades available to parents at their convenience.

5. The establishment of a warm, inviting, family-like atmosphere has been established. This provides the foundation for establishing opportunities that will enhance the school's efforts. For example, creation of a parent room with learning materials that can be checked out would likely be helpful. Efforts need to be made to increase parent volunteers. A beginning step would be to keep parents informed about help that is needed at the school. Assistance from parents can be provided in multiple ways such as making materials, reading to a class or individuals, and organizing learning materials. It also would be helpful to compile a list for the teachers' use of topics and demonstrations that parents could provide to enhance student learning.

6. The school should identify ways to reduce the number of behavioral referrals to the school office for "at-risk" students. Strategies should be identified and developed in cooperation with parents. Teachers and parents may need information and training in discipline management and diversity.

7. The school staff should review their schedule and procedures for parent/teacher conferences. Even though parents of both risk groups overwhelmingly indicate they feel informed about their children's progress in school, there was indication that the parents of non "at-risk" students may be slighted in the number of formal parent/teacher conferences. 
Children need help from their parents to succeed in school and life. Strong connections between the school and home can provide support to parents and children. This study showed that parents, students, and teachers have favorable perceptions of Metter Intermediate School. The school facilitated numerous connections between the school and the home. Positive relationships that have been established can provide the basis for increased support to families in relation to their children's academic success. Parental involvement is recognized and promoted as very important for the education of students. The engagement of parents continues to be a challenge. Perhaps further understanding could be realized by conducting studies similar to this study. It would likely be helpful to study the implementation of school-home partnership models with various types of school populations and settings. Special attention should be given to parents who are non-participants in the school. This would likely increase the understanding of the needs of families. 


\section{REFERENCES}

Blendinger, J., \& Jones, L. T. (2003). Reaching out to families. Dubuque, IA: Kendall/Hunt Publishing.

Comer, J. P. (1988). Is parenting essential to good teaching? National Education Association, 6, 34-40.

Davies, D. (1991). Schools reaching out: Family, school, and community partnerships or student success. Phi Delta Kappan, 72 (5), 376-382.

Davies, D. (2001). Family participation in decision making and advocacy. In Diana B. Hiatt-Michael (Ed.), Promising practices for family involvement in schools (pp.107-151). Greenwich, CT: Information Age Publishing.

Davies, D. (2000). Powerful partnerships among schools, parents, and communities. Principal 80, 32-34.

Dillman, D.A.(1978), Mail \& Telephone Surveys. New York: John Wiley \& Sons.

Drake, D. D. (2000). Parents and families as partners in the education process: Collaboration for the success of students in public schools. ERS Spectrum, 18, 34-39.

Edwards, P. A. (1999) School-family connections: Why are they so difficult to create? In W.D. Hammond \& T.E. Raphael (Eds.), Early literacy instruction for the new millennium (pp. 73-91). Grand Rapids, MI \& Ann Arbor, MI: Michigan Reading Association \& the Center for the Improvement of Early Reading Achievement, University of Michigan.

Epstein, J. L. (1992). School and family partnerships. Center on families, communities, schools and children's learning, Report No. 6, 1-25.

Epstein, J.L. (1995). School/family/community partnerships: Caring for the children we share. Phi Delta Kappan, 75, 701-712. 
Epstein, J. L., Coates, L., Salinas, K. C., Sanders, M. G., \& Simon, B. S. (1997). School, family, and community partnerships: Your handbook for action. Thousand Oaks, CA: Corwin Press.

Family Connection Partnership (n.d.) Who we are. Retrieved November 10, 2002 from http://www.georgiafamilyconnection.org/whoweare/whoweare.htm

Georgia Department of Education. (1999). Georgia criterion-referenced tests: CRCT content descriptors. Atlanta, GA: Author.

Georgia School Council Institute. (2000). Georgia School Council Handbook. Atlanta, GA: Author.

Gordon, I. J. \& Breivogel, W. F (1976). Building effective home/school relationships, Boston: Allyn and Bacon.

Gravetter, F.J., \& Wallnau, L. B. (2000). Statistics for the Behavioral Science. Belmont, CA: Wadsworth/Thomson Learning.

Haynes, N. M., Comer, J. P., \& Hamilton-Lee, M. (1989). School climate enhancement through parental involvement. Journal of School Psychology, 27, 87-90.

Henderson, A. T., \& Berla, N.(1994). A new generation of evidence: The family is critical to student achievement. St. Louis, MO: Danforth Foundation and Flint, MI: Mott Foundation.

Henderson, A. T., \& Mapp, K. (2002). A new wave of evidence: The impact of school, family, and community connections on student achievement. Austin, TX: Southwest Educational Development Laboratory.

Heymann, S. J. \& Earle, A., (2000). Low-income parents: How do working conditions affect their opportunity to help school-age children at risk? American Educational Research Journal 37 (4), 833-848.

Hiatt-Michael, D. B. (2001). Home-school communication. In Diana B. HiattMichael (Ed.), Promising practices for family involvement in schools (pp. 39-57). Greenwich, CT: Information Age Publishing.

Interstate School Leaders Licensure Consortium (1996, November 2). Standards for school leaders. Retrieved October 26, 2003, from http//www.mpa.cc/pdf/isllc.pdf. 
Kaplan, D.S.,Liu, X.,Kaplan, H. B. (2000). Family structure and parental involvement in the intergenerational parallelism of school adversity. Journal of Educational Research, 93 (4) 235-245.

Kelleghan, T., Sloane, K., Alvarez, B., \& Bloom, B. S. (1993). The home environment and school learning. San Francisco: Josey-Bass.

Kirschenbaum, H. (2001). Educating professionals for school, family, and community paratnerships. In Diana B. Hiatt-Michael (Ed.), Promising practices for family involvement in schools (pp.185-208). Greenwich, CT: Information Age Publishing.

McCarthey, S. J. (2000). Home-school connections: A review of the literature. Journal of Eclucational Research 93 (3), 145-153.

National Board of Professional Teaching Standards (n.d.). Retrieved September 9, 2001, from http://gseweb.harvard.edu/ hfrp/projects/fine/standardsdatabase/nbptsprofile.html.

National P'TA. (2000). Building successful partnerships: A guide for developing parent and family involvement programs. Bloomington, Indiana: Author.

No Child Left Behind Act of 2001, U.S. C. S. § 6301 et seq. (Lexis, 2005).

Olmsted, P. P., Rubin, R. I., True, J.H., Revicki, D.A. (1980). The contributions of Ira J Gorlon. Washington, DC: Association for Childhood Education International.

Riehl, C. J.. (2000). The principal's role in creating inclusive schools for diverse students: A review of normative, empirical, and critical literature on the practice of educational administration. Review of Educational Research, 70, no. 1, 55-81.

Slavin, R. E. \& Madden, N. A. (1989). What works for students at risk. Educational Leadership 45 (5) 4-13.

Swap, S. M. (1993). Developing home-school partnerships: From concepts to practice. New York: Teachers College Press.

Watkins, T. J. (1997). Teacher commjnications, child achievement, and parent traits in parent involvement models. Journal of Educational Research 91 (1) 3-14. 
Weiss, H., Kreider, H., Levine, E., Mayer, E., Stadler, J., \& Vaughan, P. (1998, April). Beyond the parent-teacher conference: Diverse patterns of home-school communicution. Symposium conducted at the meeting of the American Educational Research Association, San Diego, CA.

U.S. Department of Education. (1994). Goals 2000: National education goals. Washington, D.C.: Author.

Yin, R.K. (1994). Case Study Research. Thousand Oaks, CA: Sage Publications. 
APPENDIX A

APPROVAL DOCUMENTS 


\section{Missíssiplpis State}

PIName: Janice W. Waters

Addiess: P. O. Box 611

Melfer, (ia. 3013?

Arlvisol: I)r.W. C. Johmson

\section{CONIINUING REVIEW REPORT FORM}

IRP Iockel \#04.064

Project Tille: Impact of a Schmol Ilomen

Partuetship Model at a Small, Rmal

Flementary Sc:hool in Geolugia

Expiration dafe: $\Lambda_{p}$ il 15,2005

Finding status: I Inwarded List aggency:

I IPending I Not awarded xNo cost sturly

1. Number of subjects involved in the project (to date, if ongoing): 307

2. Were there any adverse events or manticipated problems?

I.IYES, Provide a detailed statement:

xNO

3. Number of subjects who withdrew from the project: none

4. Were there any complaints regarding the project?

I IYES, Provide a detailed statement:

$x \mathrm{NO}$

5. Is there any new information since the last IRB review that michth impact the Board's understanding of the risks or benefits?

LIYES, Provide a detailed statement:

$x \mathrm{NO}$

6. Has the project been modified since the last IRB review?

XYES, Have all changes been submitted for IRB approval: xYES I INO LJNO

7. Are you still collecting data? LIYES xNO

8. Are your remaining activities confined to clata analysis? XYES I INO

9. Projected end of project (data analysis complete): April 15, 2006

10. Please atlach a current consent form.
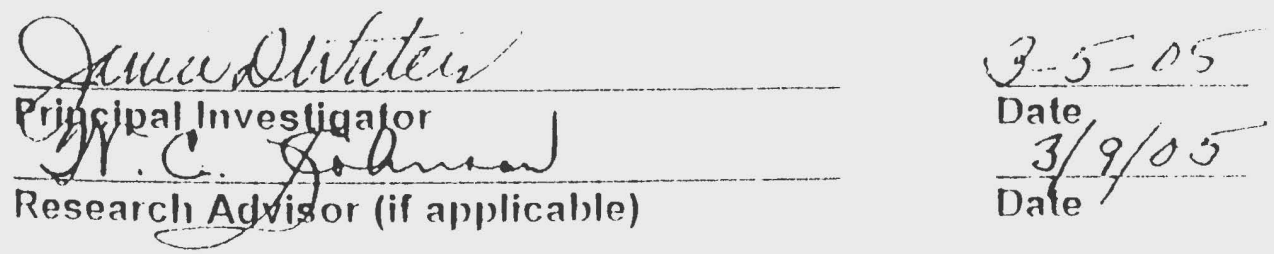

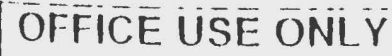
Adminishalive

$\checkmark$ Tixpediled liull Boand

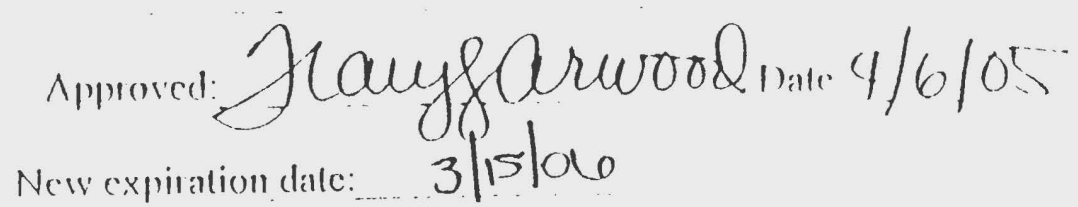

1 


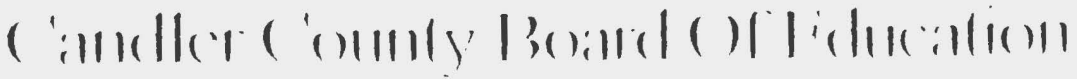

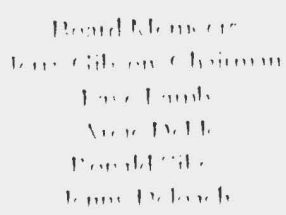

nlis. Jamier W. Walces

Meller Infermentialeselmenl

1). Wrest Vellis Sterel

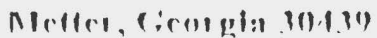

Mrar Mhs. W:ace:

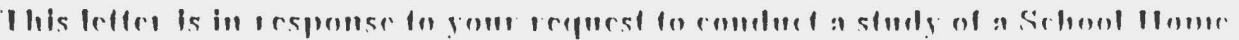

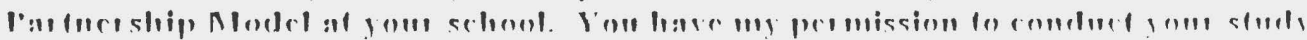

lot youl dissctintion.

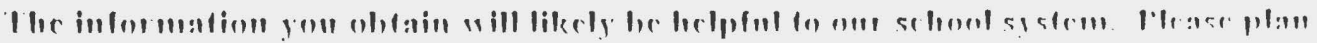

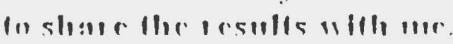

Simererly,<smiles>CC=C(C)C(C)(C)OCC</smiles>

11) Jicliv Inhuslun 
APPENDIX B

TEACHER SURVEY 


\section{TEACHER SURVEY}

Please complete the following survey that will help us better understand your perspective about Metter Intermediate School. Your input and suggestions are very important for the improvement of our school. You do not need to include your name. Please place your completed survey in the addressed, postage-paid envelope and mail it. The results will be compiled and shared with you at a later date.

Please indicate your response for each item by circling one of four choices: strongly agree, agree, disagree, or strongly disagree.

1. I provide information about my students' progress so that parents know how their children are performing in school.

$$
\text { Strongly agree agree disagree strongly disagree }
$$

2. I have had at least one face-to-face conference with all parents of my homeroom students this school year.

$$
\text { Strongly agree agree disagree strongly disagree }
$$

3. I effectively communicate both positive and negative news about students to their parents.

$$
\text { Strongly agree agree disagree strongly disagree }
$$

4. I treat concerns about students with respect and genuine interest in developing solutions.

$$
\text { Strongly agree agree disagree strongly disagree }
$$

5. I communicate student expectations to the parents of my students.

$$
\text { Strongly agree agree disagree strongly disagree }
$$

6. The community supports Metter Intermediate School.

$$
\text { Strongly agree agree disagree strongly disagree }
$$


7. I respond promptly to parent notes and phone calls.

$$
\text { Strongly agree agree disagree strongly disagree }
$$

8. Parents should be involved in students' education.

$$
\text { Strongly agree agree disagree strongly disagree }
$$

9. The meetings at our school (for example, Open House, Parent Orientation, PTO, MIS School Council) are interesting and helpful.

$$
\text { Strongly agree agree disagree strongly disagree }
$$

10. I make parents feel valued and welcomed at our school.

$$
\text { Strongly agree agree disagree strongly disagree }
$$

11. I regularly communicate to parents about what is being taught in my classes.

$$
\text { Strongly agree agree disagree strongly disagree }
$$

12. I am effective in helping parents know how to help students complete assignments and make good grades.

$$
\text { Strongly agree agree disagree strongly disagree }
$$

13. Community involvement is important for a good school.

$$
\text { Strongly agree agree disagree strongly disagree }
$$

14. Our school has an active and effective parent organization (PTO).

$$
\text { Strongly agree agree disagree strongly disagree }
$$

15. People from our community (for example, police officers, nurses, firemen, etc) come to the school to help students learn important information.

$$
\text { Strongly agree agree disagree strongly disagree }
$$

16. I have input into decisions about parent and community involvement at our school.

$$
\text { Strongly agree agree disagree strongly disagree }
$$


17. The parents of my students regularly attend PTO meetings.

$$
\text { Strongly agree agree disagree strongly disagree }
$$

18. I request information from parents on their children's talents, interests, or needs.

$$
\text { Strongly agree agree disagree strongly disagree }
$$

Please complete the following short answer responses:

The two most effective things that I do to keep parents informed about their child's progress in school are:

Please give comments about how we could improve parent and/or community involvement at Metter Intermediate School: 
APPENDIX C

\section{INFORMED CONSENT DOCUMENT}

FOR TEACHER SURVEY 
To: MIS Teachers

From: Janice D. Waters

Date: April 1, 2004

As a part of my graduate work at Mississippi State University, I am conducting a research study of our school. In this letter I am requesting your help with my study. I am also providing you with information about my study as required by Mississippi State University Institutional Review Board For the Protection of Human Subjects in Research. I would like for you to complete a brief survey about MIS. If you give your permission, I will give you a short survey to complete. I would anticipate that the survey would take less than fifteen minutes to complete. I will include a stamped, addressed envelope so that you can return it. You will not need to include your name on the survey.

The title of my study is "Impact of a School-Home Partnership Model at a Small Rural, Elementary School in Georgia." The School-Home Partnership Model was created by the administration of MIS for the purpose of increasing involvement of families in their children's education. The model was designed to improve academic achievement and behavior. I want to know if the partnership model increased parent involvement, improved students' academic success, or promoted appropriate behavior. Your participation will help by giving your ideas about family involvement.

The research will be conducted by surveying MIS students and their parents and teachers at Metter Intermediate School. Also, teachers will be interviewed. I will review parent participation records, report card grades, attendance records, and discipline records.

All information will be kept confidential. No personally identifiable information will be used. However, I am required to tell you that these records will be held by a state entity and therefore are subject to disclosure if required by law.

If you have any questions about this research project, please feel free to contact me at 912-685-6851. For additional information regarding your rights as a research subject, please feel free to contact the Mississippi State University Regulatory Compliance Office at 662-325-3294.

Please understand that your participation is voluntary. Your refusal to participate will involve no penalty to you. If you are willing to participate by completing the survey, please sign one copy of this form and return it to my school mailbox. Please keep the other copy of this form for your records.

Participant

Signature Date

Investigator

Signature Date 
APPENDIX D

STUDENT SURVEY

("AT-RISK" STUDENTS) 


\section{STUDENT SURVEY}

Please complete the following survey that will help us better understand your ideas about Metter Intermediate School. Your ideas are very important and will help us to improve our school. You do not need to put your name on this survey.

Please indicate your response for each item by circling one of four choices: strongly agree, agree, disagree, or strongly disagree.

1. My parent/s usually help me with my homework.

Strongly agree agree disagree strongly disagree

2. I use my agenda to help me get my schoolwork completed.

Strongly agree agree disagree strongly disagree

3. My parents feel welcome at my school.

Strongly agree agree disagree strongly disagree

4. My parent/s volunteer to do things in my school or classroom.

Strongly agree agree disagree strongly disagree

5. My parents come to school meetings and events.

Strongly agree agree disagree strongly disagree

6. My teachers send home my work for my parents to see.

Strongly agree agree disagree strongly disagree

7. My teachers send notes home to my parent/s.

Strongly agree agree disagree strongly disagree 
8. My teachers call my parent/s.

$$
\text { Strongly agree agree disagree strongly disagree }
$$

9. My teachers send email messages to my parent/s.

$$
\text { Strongly agree agree disagree strongly disagree }
$$

10. My teachers send invitations to my parent/s for school programs, class celebrations, and other special events.

$$
\text { Strongly agree agree disagree strongly disagree }
$$

11. My parent/s know what I'm studying at school.

$$
\text { Strongly agree agree disagree strongly disagree }
$$

12. People from our community (for example nurses, firemen, police officers) come to my school to help me learn important information.

$$
\text { Strongly agree agree disagree strongly disagree }
$$

Thank you for responding to the 12 items. Now please complete the following short answer response:

What would make Metter Intermediate School a better school? 
APPENDIX E

STUDENT SURVEY

(NON “AT-RISK” STUDENTS) 


\section{STUDENT SURVEY}

Please complete the following survey that will help us better understand your ideas about Metter Intermediate School. Your ideas are very important and will help us to improve our school. You do not need to put your name on this survey.

Please indicate your response for each item by circling one of four choices: strongly agree, agree, disagree, or strongly disagree.

1. My parent/s usually help me with my homework.

$$
\text { Strongly agree agree disagree strongly disagree }
$$

2. I use my agenda to help me get my schoolwork completed.

$$
\text { Strongly agree agree disagree strongly disagree }
$$

3. My parents feel welcome at my school.

$$
\text { Strongly agree agree disagree strongly disagree }
$$

4. My parent/s volunteer to do things in my school or classroom.

$$
\text { Strongly agree agree disagree strongly disagree }
$$

5. My parents come to school meetings and events.

$$
\text { Strongly agree agree disagree strongly disagree }
$$

6. My teachers send home my work for my parents to see.

$$
\text { Strongly agree agree disagree strongly disagree }
$$

7. My teachers send notes home to my parent/s.

$$
\text { Strongly agree agree disagree strongly disagree }
$$

8. My teachers call my parent/s.

Strongly agree agree disagree strongly disagree 
9. My teachers send email messages to my parent/s.

$$
\text { Strongly agree agree disagree strongly disagree }
$$

10. My teachers send invitations to my parent/s for school programs, class celebrations, and other special events.

$$
\text { Strongly agree agree disagree strongly disagree }
$$

11. My parent/s know what I'm studying at school.

$$
\text { Strongly agree agree disagree strongly disagree }
$$

12. People from our community (for example nurses, firemen, police officers) come to my school to help me learn important information.

$$
\text { Strongly agree agree disagree strongly disagree }
$$

Thank you for responding to the 12 items. Now please complete the following short answer response:

What would make Metter Intermediate School a better school? 


\section{APPENDIX F \\ INFORMED CONSENT DOCUMENT \\ FOR STUDENT AND PARENT}

SURVEYS 
To: MIS Parents

From: Janice D. Waters

Date: April 1, 2004

As a part of my graduate work at Mississippi State University, I am conducting a research study about family involvement in children's education at Metter Intermediate School. I am requesting your help with my study. I would like for you and your child to complete a brief survey about MIS. This will be a one-time survey and your child will be made aware of the same information I am providing to you:

1. participation is fully voluntary

2. you can withdraw at any time

3. you may refuse to answer any question

4. responses will be kept confidential and remain anonymous.

If you give your permission, I will mail to you at the address you indicate below a short survey for you to complete. I would anticipate that the survey would take less than fifteen minutes to complete. I will include a stamped, addressed envelope so that you can return it to me. You will not need to include your name on the survey. If you give your permission for your child to complete a survey, I will give him/her an opportunity to do this at school. The student survey will take less than fifteen minutes to complete. Your child will not include his/her name on the survey.

The title of my study is "Impact of a School-Home Partnership Model at a Small Rural, Elementary School in Georgia". The model was created by the administration of MIS for the purpose of increasing involvement of families in their children's education. The model was designed to improve academic achievement and behavior. I want to know if the partnership model increased parent involvement, improved students' academic success, or promoted appropriate behavior. The participation of you and your child will help by giving yours and your child's ideas about our school.

The research will be conducted by surveying students and their parents. Teachers at Metter Intermediate School will complete surveys and interviews. I will review parent participation records, report card grades, attendance records, and discipline records.

All information will be kept confidential. No personally identifiable information will be used. However, I am required to tell you that these records will be held by a state entity and therefore are subject to disclosure if required by law.

If you have any questions about this research project, please feel free to contact me at 912-685-6851. For additional information regarding your rights as a research subject, please feel free to contact the Mississippi State University Regulatory Compliance Office at $662-325-3294$. 
Your refusal to participate will involve no penalty to you or your child. If you are willing for you and your child to participate by completing the surveys, please sign one copy of this form and let your child return the signed form to school. Please keep the other copy of this form for your records.

Child's

Name

Parent's

Signature Date

Please mail my survey to this address:

Investigator's Signature: 
APPENDIX G

ASSENT DOCUMENT FOR STUDENT SURVEYS 
To: MIS Student

From: Janice D. Waters

Date: April 1, 2004

Your parent knows we are going to ask you to participate in this survey. We want to know about students' attitudes and experiences about family involvement in our school. It will take about fifteen minutes of your time to complete the survey. Your name will not be written anywhere on the survey. No one will know these answers come from you personally.

If you don't want to participate, you can stop at any time. There will be no bad feelings if you don't want to do this. You can ask questions if you do not understand any part of the survey.

Do you understand? Is this OK?

Name (Please print)

Signature:

Date:

Investigator's Signature:

Date 
APPENDIX H

PARENT SURVEY

(FOR “AT-RISK” STUDENTS) 


\section{PARENT SURVEY}

Please complete the following survey. Your responses will help us better understand your perspective (text shifted on this copy to show that "about" appeared at beginning of line") about Metter Intermediate School. Your input and suggestions are very important.

Please place the completed survey in the addressed, postage-paid envelope and mail it. If you prefer, you can return the survey to your child's teacher. You do not need to include your name. Responses will be compiled and shared with you at a later date.

Please indicate your response for each item by circling one of four choices: strongly agree, agree, disagree, or strongly disagree.

1. I am provided enough information about my child's progress so that I know how he/she is performing in school.

$$
\text { Strongly agree agree disagree strongly disagree }
$$

2. I have had at least one face-to-face conference with my child's homeroom teacher this school year.

$$
\text { Strongly agree agree disagree strongly disagree }
$$

3. I am confident that I can easily contact my child's homeroom teacher if a problem arises.

$$
\text { Strongly agree agree disagree strongly disagree }
$$

4. My child's teacher sends home student work for me to review on a regular basis.

$$
\text { Strongly agree agree disagree strongly disagree }
$$

5. My child's teachers effectively communicate both positive and negative news about my child.

$$
\text { Strongly agree agree disagree strongly disagree }
$$

6. My concerns about my child are treated with respect and genuine interest in developing solutions.

Strongly agree agree disagree strongly disagree 
7. I know what is expected of me by MIS in order to help my child experience success.

$$
\text { Strongly agree agree disagree strongly disagree }
$$

8. Community members come to our school to help students learn important information.

$$
\text { Strongly agree agree disagree strongly disagree }
$$

9. I am knowledgeable about programs and activities at Metter Intermediate School.

$$
\text { Strongly agree agree disagree strongly disagree }
$$

10. The meetings I have attended at Metter Intermediate School this year (for example: Open House, Parent Orientation, PTO, School Council) have been interesting and helpful.

$$
\text { Strongly agree agree disagree strongly disagree }
$$

11. My child's teacher knows and appreciates my child's unique abilities and interests.

$$
\text { Strongly agree agree disagree strongly disagree }
$$

12. I feel welcome at Metter Intermediate School.

Strongly agree agree disagree strongly disagree

13. My child's agenda provides helpful information about what is studied in school.

Strongly agree agree disagree strongly disagree

14. My child's teacher/s regularly communicates with me about what is being taught.

Strongly agree agree disagree strongly disagree

15. I feel that I can help my child complete assignments and make good grades.

Strongly agree agree disagree strongly disagree 
16. I have input into decisions that are made at the school.

$$
\text { Strongly agree agree disagree strongly disagree }
$$

17. The community supports Metter Intermediate School.

Strongly agree agree disagree strongly disagree

18. I regularly attend Parent Teacher Organization (PTO) meetings and other special events at the school.

Strongly agree agree disagree strongly disagree

19. I volunteer to help in my child's classroom or the school in general.

Strongly agree agree disagree strongly disagree

20. I could better assist my child learn if teachers gave me more ideas.

Strongly agree agree disagree strongly disagree

Thank you for responding to the 20 items. Now please complete the following short answer responses:

The most helpful things that my child's teacher/s do to help my child in school are:

How could Metter Intermediate School better serve you and your child? 


\section{APPENDIX I}

\section{PARENT SURVEY}

(FOR NON “AT- RISK” STUDENTS) 


\section{PARENT SURVEY}

Please complete the following survey. Your responses will help us better understand your perspective about (text on actual survey had the word "about" at end of first line of text) Metter Intermediate School. Your input and suggestions are very important. Please place the completed survey in the addressed, postage-paid envelope and mail it. If you prefer, you can return the survey to your child's teacher. You do not need to include your name. Responses will be compiled and shared with you at a later date.

Please indicate your response for each item by circling one of four choices: strongly agree, agree, disagree, or strongly disagree.

1. I am provided enough information about my child's progress so that I know how he/she is performing in school.

$$
\text { Strongly agree agree disagree strongly disagree }
$$

2. I have had at least one face-to-face conference with my child's homeroom teacher this school year.

$$
\text { Strongly agree agree disagree strongly disagree }
$$

3. I am confident that I can easily contact my child's homeroom teacher if a problem arises.

Strongly agree agree disagree strongly disagree

4. My child's teacher sends home student work for me to review on a regular basis.

Strongly agree agree disagree strongly disagree

5. My child's teachers effectively communicate both positive and negative news about my child.

Strongly agree agree disagree strongly disagree 
6. My concerns about my child are treated with respect and genuine interest in developing solutions.

$$
\text { Strongly agree agree disagree strongly disagree }
$$

7. I know what is expected of me by MIS in order to help my child experience success.

$$
\text { Strongly agree agree disagree strongly disagree }
$$

8. Community members come to our school to help students learn important information.

$$
\text { Strongly agree agree disagree strongly disagree }
$$

9. I am knowledgeable about programs and activities at Metter Intermediate School.

$$
\text { Strongly agree agree disagree strongly disagree }
$$

10. The meetings I have attended at Metter Intermediate School this year (for example: Open House, Parent Orientation, PTO, School Council) have been interesting and helpful.

$$
\text { Strongly agree agree disagree strongly disagree }
$$

11. My child's teacher knows and appreciates my child's unique abilities and interests.

$$
\text { Strongly agree agree disagree strongly disagree }
$$

12. I feel welcome at Metter Intermediate School.

Strongly agree agree disagree strongly disagree

13. My child's agenda provides helpful information about what is studied in school.

Strongly agree agree disagree strongly disagree

14. My child's teacher/s regularly communicates with me about what is being taught.

Strongly agree agree disagree strongly disagree 
15. I feel that I can help my child complete assignments and make good grades.

$$
\text { Strongly agree agree disagree strongly disagree }
$$

16. I have input into decisions that are made at the school.

$$
\text { Strongly agree agree disagree strongly disagree }
$$

17. The community supports Metter Intermediate School.

$$
\text { Strongly agree agree disagree strongly disagree }
$$

18. I regularly attend Parent Teacher Organization (PTO) meetings and other special events at the school.

$$
\text { Strongly agree agree disagree strongly disagree }
$$

19. I volunteer to help in my child's classroom or the school in general.

$$
\text { Strongly agree agree disagree strongly disagree }
$$

20. I could better assist my child learn if teachers gave me more ideas.

Strongly agree agree disagree strongly disagree

Thank you for responding to the 20 items. Now please complete the following short answer responses:

The most helpful things that my child's teacher/s do to help my child in school are: 
APPENDIX J

INFORMED CONSENT DOCUMENT

FOR TEACHER INTERVIEWS 
To: MIS Teachers

From: Janice D. Waters

Date: April 1, 2004

As a part of my graduate work at Mississippi State University, I am conducting a research study of our school. In this letter I am requesting your help with my study. I am also providing you with information about my study as required by Mississippi State University Institutional Review Board for the Protection of Human Subjects in Research.

The title of my study is "Impact of a School-Home Partnership Model at a Small Rural, Elementary School in Georgia". The model was created by the administration of MIS for the purpose of increasing involvement of families in their children's education. The model was designed to improve academic achievement and behavior. I want to know if the model increased parent involvement, improved student's academic success, or promoted appropriate behavior. Your participation will help by giving your ideas about family involvement.

I would like for you to participate in an individual interview with me. If you give your consent, I will arrange a date and time convenient for us to meet. The interview will take about thirty minutes. I plan to audiotape your responses to ensure that the information is accurately interpreted. A set of questions has been developed to which you will be asked to respond, such as "What are the best ways to keep parents informed about their child's progress in school?" I understand that you reserve the right to refuse to answer any question and to withdraw from the study at any time.

All information will be kept confidential. No identifiable responses will be used in the study. However, I am required to tell you that these records will be held by a state entity and therefore are subject to disclosure if required by law.

If you have any questions about this research project, please feel free to contact me at 912-685-6851. For additional information regarding your rights as a research subject, please feel free to contact the Mississippi State University Regulatory Compliance Office at 662-325-3294. Please understand that your participation is voluntary. Your refusal to participate will involve no penalty to you. If you are willing to participate in the interview, please sign one copy of this form and return it to my school mailbox. Please keep the other copy of this form for your records.

Participant's Signature Date Date 
APPENDIX K

INTERVIEW QUESTIONS FOR TEACHERS 
Interview Questions for Teachers

1. How are parents involved at our school?

2. What are the best ways to keep parents informed about their child's progress in school?

3. In what ways do you communicate with parents? Which ways are the most effective?

4. What strategies do you use to get to know your students and their parents?

5. Do you ever invite parents to come to school? If yes, tell some of the reasons you have invited them. What were the results?

6. What is the role of the teacher in home-school communication?

7. How could our school increase parent participation in children's education? What differences, if any, are there between involving parents of at-risk students (special education or Early Intervention Program students) and non at-risk students?

8. Do you give any specific help to parents in order for them to assist their child with academics? If so, please explain.

9. What are the advantages/disadvantages of our school agendas? How can we use them more effectively?

10. Is there anything else you would like to say about our school? What can we do to improve home-school communication, student behavior, and academic success? 
